\title{
Revealing ancient gold parting with silver and copper isotopes: implications from cementation experiments and for the analysis of gold artefacts
}

\author{
Daniel Berger $^{1}$ (D) Michael Brauns $^{1} \cdot$ Gerhard Brügmann $^{1}$ (D) Ernst Pernicka ${ }^{1,2}$ (D) Nicole Lockhoff $^{1}$
}

Received: 5 February 2021 / Accepted: 31 May 2021 / Published online: 6 August 2021

(C) The Author(s) 2021

\begin{abstract}
Gold parting enabled the production of very pure gold for various purposes from the sixth century BC onwards, but analytical proof of this pyrotechnical process is difficult. We describe a new analytical approach for the identification of purified gold combining silver and copper isotopic with trace element analyses. Parting experiments were performed with gold-silver-copper alloys using the classical salt cementation process to investigate potential silver and copper isotope fractionation and changes in trace element concentrations. In addition, we provide the first comprehensive dataset of silver isotope ratios of archaeological gold objects from the Mediterranean and Central Europe to test whether or not gold refining can be identified on the basis of isotope systematics. The results show that very heavy silver and copper isotopic compositions are clear evidence for parted gold, but that the application of copper isotopes might be limited.
\end{abstract}

Keywords Gold parting · Cementation · Gold · Stable silver isotopes · Stable copper isotopes · Roman era · Prehistory · Mediterranean · Central Europe

\section{Introduction}

The ancient process of gold parting-a gold refining process - is closely linked to the antique Lydian kingdom and its capital Sardis. Ruins of the ancient city are located near Izmir in western Turkey and seem to be the only remains of an empire that ruled in its heyday almost half of Anatolia. The Lydians were known by contemporaries for their extraordinary wealth. This legendary prosperity is particularly associated with the last Lydian king Croesus and was primarily based on alluvial gold deposits in the sands of the nearby rivers and lodes in the Tmolus Mountains (e.g. Herodotus

Daniel Berger

daniel.berger@ceza.de

Ernst Pernicka

ernst.pernicka@ceza.de

1 Curt-Engelhorn-Zentrum Archäometrie gGmbH, D6, 3, 68159 Mannheim, Germany

2 Institute of Prehistory, Early History and Medieval Archaeology, University of Tübingen, Schloss Hohentübingen,

72070 Tübingen, Germany
1904, Book I.30-32; Ramage and Craddock 2000). However, it was the discovery of a metallurgical workshop during archaeological excavations at Sardis in the late 1960s that contributed to a better understanding of the cultural context (Ramage and Craddock 2000, 14-26). The excavations brought to light the remains of a gold refinery from the middle of the sixth century $\mathrm{BC}$, which produced almost pure gold by applying a cementation technique. The metallurgical vestiges are unique in their extent and combination and are seen as the inception of gold refining under the reign of Croesus. In this context, the invention of gold parting at this place is revolutionary as it is contemporary with the earliest minting of coinage and may well have paved the way for monetary economics. Coins made of pure gold and silver as well as gold-silver alloys with defined compositions were now possible and a major prerequisite in this respect (Cowell and Hyne 2000). Archaeological evidence for gold cementation is also known from later periods and other sites, such as parting vessels from Roman and early mediaeval Britain (Bayley 1991, 1992; Bayley et al. 2008, 30-33). Furthermore, pyrometallurgical remains in the Limousin in France could suggest some kind of gold refining (Cauuet et al. 2018). Because the technical ceramics from that site seem to differ from the aforementioned pieces and no other materials indicating the technological 
process were found, the interpretation as a vessel for gold cementation is not clear in this case.

It may be worthwhile to add a note on terminology. There are many different cementation processes in metallurgy - for instance in brass making and carburising iron (Craddock 2003; Bourgarit and Thomas 2008); salt parting is just one of these cementation processes. Equally, at other times, there are other parting processes in use to separate silver from gold (see chapter 2.), e.g. acid parting in the late mediaeval period and the modern era. Accordingly, the terms 'parting' and 'cementation' used synonymously in this text refer to 'salt parting' and 'salt cementation'.

The pyrometallurgical process of gold cementation is straightforward, as it simply involves the reaction of a mixture of common salt $(\mathrm{NaCl})$ and powdered fired clay (e.g. powdered pottery sherds) with impure gold alloys at medium-high temperatures. During the process, impurities of silver (Ag), copper $(\mathrm{Cu})$ and base metals are converted to liquid chlorides and are thus effectively separated from the gold. The results are gold alloys with low Ag concentrations usually less than ca. $2 \%$ or even almost pure gold. For cementation to be successful, the gold must be in the form of thin foils, because the metal remains in the solid state throughout the entire process and the reaction is limited to a small volume near the gold surface. Ancient and mediaeval written sources report on this and provide instructions on how the refining process should be carried out (see, e.g. review in Celauro et al. 2017). Many recent experiments have shown that the salt cementation process is in fact an effective and a rather simple pyrometallurgical technique (Notton 1974; Craddock 2000b; Geçkinli et al. 2000; Wunderlich et al. 2014; Blet-Lemarquand et al. 2014, 2017; Celauro et al. 2017).

The simplicity of the procedure suggests that the cementation process could have been used already before the time of the Lydian kingdom (Craddock 2000a). A small number of gold artefacts with Ag contents below $1 \%$ and an even larger number with up to $3 \% \mathrm{Ag}$ are known, for example, from the Bronze and Iron Age in Europe and the Mediterranean (Hartmann 1970, 1982; Hatchfield and Newman 1991; Klemm and Gebhard 2001; Troalen et al. 2009; Konstantinidi-Syvridi et al. 2014, Figs. 8-12; Berger 2016; Schwab and Pernicka 2021; unpublished analyses by CEZA Mannheim, M. Numrich, N. Lockhoff) as well as from the Iron Age in Vietnam (Reinecke 2019; Reinecke et al. 2019). Some of these Ag-poor gold artefacts may not stand up to critical evaluation, because their origins and datings are either unclear or they are even considered to be forgeries (Pernicka et al. 2019). Among these are the alleged Middle Bronze Age gold objects from Bernstorf, Freising district, Germany, and the Early Bronze Age gold disc from Moordorf, Aurich district, Germany, with tens of microgram per gram and $0.2 \%$ of Ag, respectively (Pernicka 2014; Pernicka et al. 2019). Other objects are instead less suspicious and, given their low Ag contents, open up the possibility of early gold parting. The development of monetary systems certainly catalysed the production of purified gold, but there may have been additional motives for earlier manipulations of gold, for example to improve the mechanical properties and especially the colour as a decorative element on prestige objects.

Unfortunately, it is still not possible to decide unambiguously whether early low-silver gold objects were produced from refined or native gold, e.g. by the trace element composition. There is alluvial gold with low concentrations of $\mathrm{Ag}$ and some trace elements (Bendall 2003; Schmiderer 2008; Jansen 2019; Pernicka et al. 2019; Borg et al. 2019) due to natural depletion by the dissolution of the less noble elements. Such gold cannot be distinguished per se from parted gold as natural depletion usually affects the same elements (BletLemarquand et al. 2014, 2017). Therefore, we pursued a new approach to identify artefacts consisting of parted gold among those with low $\mathrm{Ag}$ contents by determining the $\mathrm{Ag}$ and $\mathrm{Cu}$ isotopic composition. In recent years, considerable analytical advances for both isotope systems were made, which have enabled systematic studies of isotope variations in natural systems, such as metal deposits, and have improved the understanding of fractionation mechanisms. They also opened up new applications in archaeometallurgy. Questions are related either to geological, metallogenetic and environmental topics (Argapadmi et al. 2018; Mathur et al. 2018; Schleicher et al. 2020) or to the provenance of archaeological silver and gold objects (Desaulty et al. 2011; Desaulty and Albarède 2013; Albarède et al. 2016; Baron et al. 2019; Milot et al. 2021). Even earlier, variations of the isotope ratios of $\mathrm{Cu}$ were intensively explored with the same purpose in the geosciences ( $\mathrm{Zhu}$ et al. 2000; Mathur et al. 2010) and in archaeometallurgy, particularly in the study of copper-based metals and rarely of gold (Klein et al. 2010; Jansen 2019). The current study presents an experimental approach to study chemical and isotopic changes of $\mathrm{Ag}$ and $\mathrm{Cu}$ during the salt cementation process on ternary gold alloys. Furthermore, it tests the validity of the results by analysing a series of archaeological gold objects from Central Europe and beyond.

\section{A brief history of refining}

Cementation with salt is not the only pyrometallurgical operation to refine gold. Most of the copper and base metals in gold alloys can be removed effectively by cupellation (Pernicka and Bachmann 1983; Blet-Lemarquand et al. 2017). This process involves melting the gold alloy with excess lead metal and heating the mixture to about $800^{\circ} \mathrm{C}$ under oxidising conditions, leading to the oxidation of lead and the majority of the other elements except for gold and silver. A porous reaction vessel (in prehistory consisting mostly of highly calcareous clay, later with a layer of bone ash) absorbs the liquid lead oxide with 
all impurities leaving behind a purified gold bullion that still contains all silver. The separation of silver can be achieved by cementation, and besides the salt process, a number of other materials and methods is described in ancient and mediaeval written sources (Soukup and Mayer 1997; Craddock 2000a; Wunderlich et al. 2014; Celauro et al. 2017). Among these procedures, the cementation with alum $\left(\mathrm{KAl}\left(\mathrm{SO}_{4}\right)_{2} \cdot 12 \mathrm{H}_{2} \mathrm{O}\right)$ or other sulphates in combination with $\mathrm{NaCl}$ was practiced as it was also done with sulphides such as stibnite $\left(\mathrm{Sb}_{2} \mathrm{~S}_{3}\right)$. However, the only process that is confirmed by archaeological findings is the salt cementation discovered at Sardis and other locations (Bayley 1991, 1992; Craddock 2000c).

The process was probably first described by Agatharchides of Cnidus in the second century BC (Craddock 2000a), but in more detail by Theophilus Presbyter in his treatise on the art of goldsmithing (De diversis artibus) in the eleventh century AD (Hawthorne and Smith 1979, 108-110; Brepohl 1987, 107109). Theophilus advised to use brick dust, to moisten it with urine and mix it with ordinary rock/sea salt in the ratio of 2:1 by mass (Brick dust: $\mathrm{NaCl}$ ). This mixture makes the cementation mixture (also called cement) in which the gold is embedded. Thin gold foils are an essential part of Theophilus' recipe, and he mentioned that gold should be placed alternately with the cement in a ceramic reaction vessel, avoiding contacts of the individual foils. The sealed vessel should be heated for at least one night in a furnace. The process described was presumably identical to that of Sardis, even though Craddock (2000c) does not rule out the use of alum and other sulphates as part of the active ingredients during refining. Even more uncertain is the question of the carrier of these active substances. No brick or clay dust was observed among the metallurgical debris in Sardis, but Craddock (2000c) considers it to be a necessary part of the operation. Hard evidence for such a cementation mixture is also lacking in the technical ceramics discovered elsewhere, but thin layers of sandy deposits on the interior of some vessels from Britain could be interpreted as remains of this mixture (Bayley 1991). Actually, it may not be surprising that such material was not found, because it contained all the silver that was extracted from the gold and was certainly considered as highly valuable 'slag'. This silver could then be extracted by melting with excess lead and cupellation. Indeed, at Sardis, many remains of litharge (oxidised lead, $\mathrm{PbO}$, the 'slag' of cupellation) were found in the area of the gold refinery and the cementation furnaces (Craddock 2000c, 208-210).

\section{Materials and methods}

\section{Cementation experiments}

The experiments of the present study were designed following Theophilus' recipe. This approach is similar to the experiments of Wunderlich et al. (2014), who investigated the cementation with $\mathrm{NaCl}$ alone and in combination with alum or nitre. We performed two series of experiments:

- (CM1) Cementation with $\mathrm{NaCl}(>99.8 \%$, Carl Roth, Karlsruhe, Germany) and fired clay $(<4 \mathrm{~mm}$, KOREST Restaurierungsbedarf, Meißen, Germany) and

- (CM2) Cementation with NaCl, alum (>99\%, Carl Roth, Karlsruhe, Germany) and fired clay.

Cements were prepared by mixing fired clay and $\mathrm{NaCl}$ in a ratio of $3: 1$ by mass in the CM1 test series, and fired clay, $\mathrm{NaCl}$ and alum in the ratio 3:1:0.4 in test series CM2. Two gold beads from Sulawesi, Indonesia (Fig. 1) containing $55 \%$ $\mathrm{Ag}$ and 2-3\% $\mathrm{Cu}$ with trace elements (for concentrations, see the results chapter) served as the starting material for the experiments. Before use, they were melted under reducing conditions $\left(1100{ }^{\circ} \mathrm{C}\right)$ to obtain homogenous gold alloys. The resulting gold prills were hammered into approx. $0.3-\mathrm{mm}$ thick foils and embedded in $15 \mathrm{~g}$ of moist cement (adding a few drops of distilled water) in a porcelain crucible. In order to prevent damage to the furnace, acid vapours of $\mathrm{HCl}$ and $\mathrm{H}_{2} \mathrm{SO}_{4}$ formed on heating were neutralised by covering the mixture with a layer of dolomite powder, which does not participate in the cementation reaction. The lidded crucibles were heated to $850^{\circ} \mathrm{C}$ for $12 \mathrm{~h}$ and allowed to cool down to room temperature within the electric muffle furnace.

Each test series comprised three cementation steps (CM1a-c; CM2a-c), each of which was performed with the gold from the previous cementation step in the same way as described above (Table 1). Samples for chemical and isotopic analyses were taken from the gold foils at each stage of the experiments. The original material was sampled directly after melting and hammering. After each cementation step, the gold foil was washed in ethanol to remove surface deposits and a sample was taken for the analyses. The remaining gold was re-melted under reducing conditions, hammered and resampled before the next cementation step. Throughout the entire test series, samples and residues were weighed with a Mettler Toledo high-precision balance, which was also used to weigh the silver-enriched cements after each single cementation step (Table 1). Of the pulverised and homogenised mixtures, an aliquot of $20 \mathrm{mg}$ was used for chemical and isotopic analysis.

A small set of gold samples from the experiments of Wunderlich and colleagues (2014) was included in this study. Experimental details can be found in the publication (Wunderlich et al. 2014), but the gold was basically treated the same way as in our experiments. The set comprises four samples in total with the original gold Z1 and ZA1 and the cemented gold $\mathrm{Z} 3$ (cementation with $\mathrm{NaCl}$ ) and $\mathrm{ZA} 3$ (cementation with $\mathrm{NaCl}$ and alum) (Table 1). The sample designation follows that of Wunderlich et al. (2014). 
Fig. 1 Gold artefacts analysed in this study with CEZA laboratory numbers corresponding to Table 2. Objects are depicted in different scales (photos: $\mathbf{a}$ and $\mathbf{b}$ D. Berger; c C.-H. Wunderlich; $d$ and $\mathbf{e}$ B. Armbruster; f GDKE, LA-Speyer, P. Haag-Kirchner)

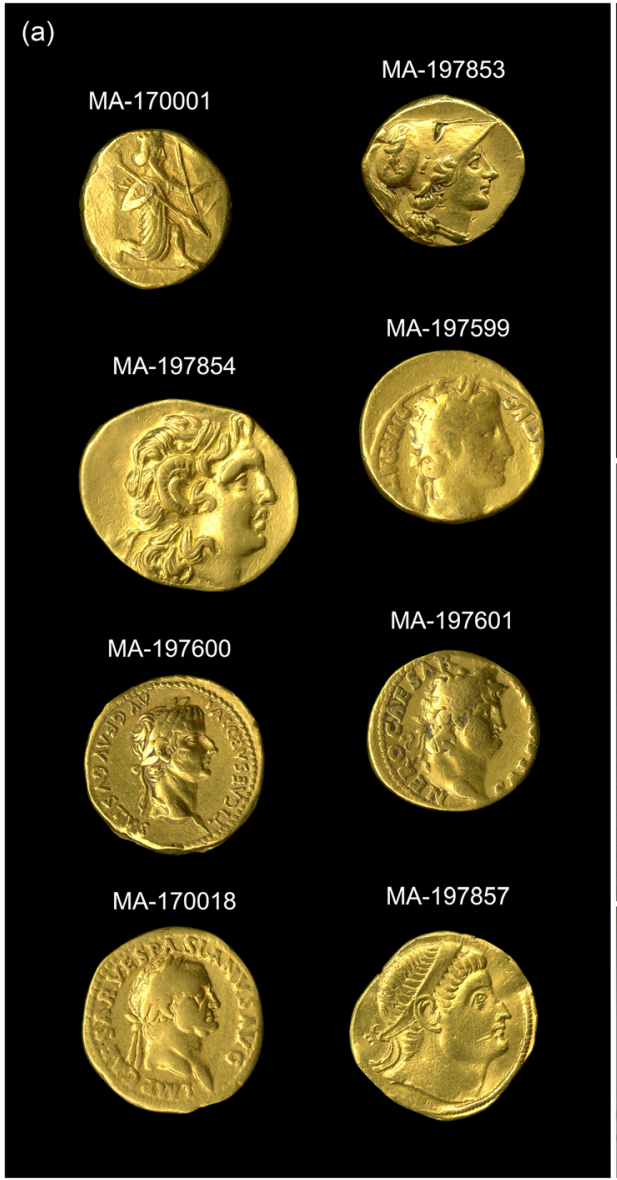

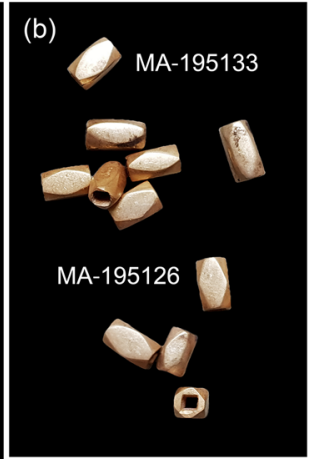
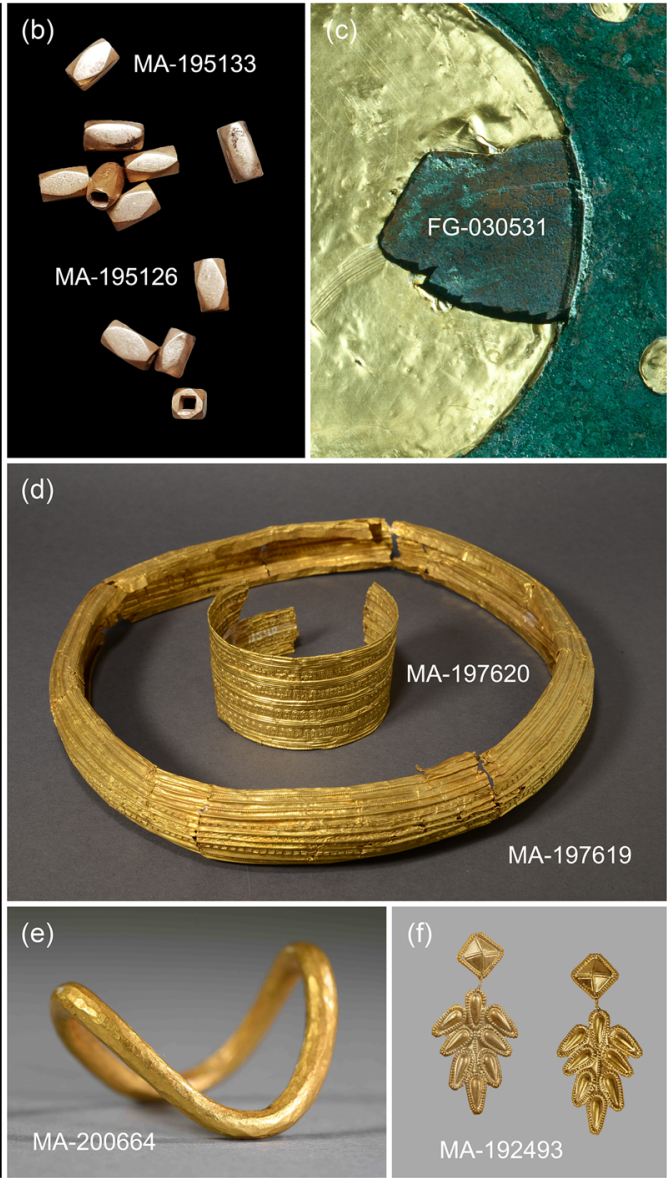

\section{Gold artefacts}

Fifteen archaeological and historical gold objects of a quite different dating were investigated in the study (Fig. 1). Apart from the two Sulawesi beads as starting material for the experiments, three non-cemented gold artefacts (11-21\% Ag, $0.2-0.4 \% \mathrm{Cu}$ ) from the Bronze and Iron Age were chosen for analysis. These are a gold foil from the Early Bronze Age Nebra Sky Disc (FG-030531) from the State Museum of Prehistory Halle (Saale), Germany, and an Early Iron Age necklace and a bracelet from Mühleberg-Allenlüften, Canton Berne, Switzerland (MA-197619; MA-197620) from the Historical Museum Berne (Hartmann 1970, Tafel 56, nos. 450 and 454; Milcent 2018). Furthermore, two other objects were analysed, which could possibly consist of cemented gold due to their low Ag contents (2-3\% Ag). One is a so-called Schaukelring (a type of finger ring) from a La Tène $\mathrm{B}$ grave (grave. no. 141) from the Dürrnberg, Austria (MA-200664) (Tiefengraber and Wiltschke-Schrotta 2012, 134-140) (Table 2). The other is one of 96 gold appliques from a Late Antique treasure trove from a clandestine excavation near Rülzheim, Germany (MA-192493) (Himmelmann 2015). Samples of all these objects were either taken during the
SAM project of A. Hartmann in the 1970s and 1980s (SAM collection in the custody of CEZA) or were provided by the museums of Halle, Hallein and Speyer for multi-analytical research.

In addition to the seven objects mentioned above, eight gold coins from Roman, Greek and Achaemenid cultural contexts were included in the sample suite. They are suspected to consist of refined gold because of their low concentrations of $\mathrm{Ag}$ between 0.12 and $3.5 \%$ and $\mathrm{Cu}$ between 0.0008 and $0.24 \%$ (Table 2). Four of these coins were Roman Aurei minted throughout the empire in the years from $8 / 7 \mathrm{BC}$ to $71 \mathrm{AD}$ under the reigns of Augustus (MA-197599), Tiberius (MA-197600), Nero (MA-197601) and Vespasian (MA-170018), and one Solidus from 324/325 AD by the ruler Constantinus I. (MA-197857). The set also includes one Achaemenid Daric (MA-170001), one Greek stater of Lysimachos (MA-197854) and one Greek 100 Litrae of Athena (MA197853) all of which were minted at different places (Sardis, Byzantium, Syracuse) some hundred years earlier than the Roman pieces (Table 2). Samples of the coins (1$3 \mathrm{mg}$ ) were taken in the CEZA laboratory using a conventional scalpel. 
Table 1 Summary of the experiments carried out in this study and samples taken for analysis

\begin{tabular}{|c|c|c|c|c|}
\hline Experiment & No. of experiment & Lab. no. & Experimental step & Time of sampling \\
\hline \multirow[t]{10}{*}{$\mathrm{NaCl}$} & CM1 & MA-195126 & Original gold & After melting and hammering the raw material \\
\hline & CM1a & MA-195828 & 1. cementation step & After cementation, as-cemented (metal rinsed) \\
\hline & CM1a & MA-195829 & 1. cementation step & After re-melting and hammering \\
\hline & CM1a & MA-195830 & 1. cementation step & Ag enriched cement \\
\hline & CM1b & MA-195831 & 2. cementation step & After cementation, as-cemented (metal rinsed) \\
\hline & CM1b & MA-195832 & 2. cementation step & After re-melting and hammering \\
\hline & CM1b & MA-195833 & 2. cementation step & Ag enriched cement \\
\hline & CM1c & MA-195834 & 3. cementation step & After cementation, as-cemented (metal rinsed) \\
\hline & CM1c & MA-195835 & 3. cementation step & After re-melting (complete metal) \\
\hline & CM1c & MA-195836 & 3. cementation step & Ag enriched cement \\
\hline \multirow[t]{10}{*}{$\mathrm{NaCl}+$ alum } & $\mathrm{CM} 2$ & MA-195133 & Original gold & After melting and forging raw material \\
\hline & $\mathrm{CM} 2 \mathrm{a}$ & MA-195837 & 1. cementation step & After cementation, as-cemented (metal rinsed) \\
\hline & $\mathrm{CM} 2 \mathrm{a}$ & MA-195838 & 1. cementation step & After re-melting and forging \\
\hline & $\mathrm{CM} 2 \mathrm{a}$ & MA-195839 & 1. cementation step & Ag enriched cement \\
\hline & $\mathrm{CM} 2 \mathrm{~b}$ & MA-195840 & 2. cementation step & After cementation, as-cemented (metal rinsed) \\
\hline & $\mathrm{CM} 2 \mathrm{~b}$ & MA-195841 & 2. cementation step & After re-melting and hammering \\
\hline & $\mathrm{CM} 2 \mathrm{~b}$ & MA-195842 & 2. cementation step & Ag enriched cement \\
\hline & $\mathrm{CM} 2 \mathrm{c}$ & MA-195843 & 3. cementation step & After cementation, as-cemented (metal rinsed) \\
\hline & $\mathrm{CM} 2 \mathrm{c}$ & MA-195844 & 3. cementation step & After re-melting (complete metal) \\
\hline & $\mathrm{CM} 2 \mathrm{c}$ & MA-195845 & 3. cementation step & Ag enriched cement \\
\hline \multirow[t]{2}{*}{$\mathrm{NaCl}$} & $\mathrm{Z1}$ & MA-135432 & Original gold & After melting and hammering the raw material \\
\hline & $\mathrm{Z3}$ & MA-135434 & 1. cementation step & After re-melting (complete metal) \\
\hline \multirow[t]{2}{*}{$\mathrm{NaCl}+$ alum } & ZA1 & MA-140384 & Original gold & After melting and hammering the raw material \\
\hline & ZA3 & MA-140386 & 1. cementation step & After re-melting (complete metal) \\
\hline
\end{tabular}

\section{Sample preparation and analytical methods}

Major $(\mathrm{Cu}, \mathrm{Ag}, \mathrm{Au})$ and trace element $(\mathrm{Ru}, \mathrm{Rh}, \mathrm{Pd}, \mathrm{Os}, \mathrm{Ir}, \mathrm{Pt}$, $\mathrm{Mn}, \mathrm{Fe}, \mathrm{Co}, \mathrm{Ni}, \mathrm{Zn}, \mathrm{As}, \mathrm{Se}, \mathrm{Cd}, \mathrm{Sn}, \mathrm{Sb}, \mathrm{Te}, \mathrm{Hg}, \mathrm{Pb}, \mathrm{Bi}$ ) concentrations in the experimental gold samples and the objects were determined by laser ablation inductively coupled plasma quadrupole mass spectrometry, LA-Q-ICP-MS (ICapQ, Thermo Fisher Scientific with Resolution M-50-E, Laser ATL, Resonetics), after the protocol published by Leusch et al. (2016). All concentrations in this paper are either reported in mass $\%(=\%)$ or in microgram per gram (earlier ppm, which is now out of use). To gain information about the (depleted) surface as well as the interior of the samples spot analyses were used. This kind of 'depth profiling' is a common procedure for analysing ancient gold and silver objects to avoid measuring the altered surfaces and to access the original alloy composition (Blet-Lemarquand and Nieto-Pelletier 2020; Sarah et al. 2007). In addition, scanning electron microscopy with X-ray microprobe, SEM-EDX (EVO MA 25, Zeiss, Oberkochen, Germany, with Quantax 400, Bruker AXS, Karlsruhe, Germany), was used to assess the surface morphology of the cemented gold and to identify adhering compounds.
The preparation of the metal samples for the analysis of the $\mathrm{Ag}$ isotopic composition is described in more detail in Brügmann et al. (2019). Hence, only the essential steps and changes compared to the original procedure are briefly described here, accompanied by a description of the treatment of the cement samples.

Depending on the Ag content in the gold, up to $10 \mathrm{mg}$ of sample material was weighed into Teflon ${ }^{\circledR}$ beakers (Savillex 5 -mL standard vials), mixed with aqua regia ( $300 \mu \mathrm{L}$ concentrated $\mathrm{HNO}_{3}+900 \mu \mathrm{L}$ concentrated $\mathrm{HCl}$ ) and placed on a hot plate at $80{ }^{\circ} \mathrm{C}$. After complete dissolution, the samples were dried down. For the removal of $\mathrm{Au}$ and other elements by column chemistry, the samples were taken up with $500 \mu \mathrm{L}$ of concentrated $\mathrm{HCl}$, diluted to $6 \mathrm{~mol} \mathrm{~L}^{-1} \mathrm{HCl}$ with deionised water and loaded on a first column containing $0.2 \mathrm{~mL}$ of the anion resin AG® 1-X8 (100-200 mesh, Bio-Rad Laboratories $\mathrm{GmbH}$, Feldkirchen, Germany). With a second column filled up with $0.2 \mathrm{~mL}$ TBP resin $(50-100 \mu \mathrm{m}$, Triskem International, Bruz, France), the sample solutions were finally transferred into the nitrate form and analysed by MC-ICP-MS.

Of the cementation mixtures between 10 and $20 \mathrm{mg}$, sample powder was weighed into Teflon ${ }^{\circledR}$ beakers (Savillex 
Table 2 Gold artefacts analysed in the present study

\begin{tabular}{|c|c|c|c|c|c|}
\hline Lab. no. & Artefact & Find location & Dating & Original number & Collection \\
\hline FG-030531 & Nebra Sky Disc, sun & Nebra, Germany & Ca. 1600 BC & HK 2002:1649 a & $\begin{array}{l}\text { State Museum of Prehistory, } \\
\text { Halle }\end{array}$ \\
\hline MA-197619 & Necklace & Allenlüften, Switzerland & Ha D2 & 11536-39 (SAM 450) & Historical Museum, Berne \\
\hline MA-197620 & Bracelet & Allenlüften, Switzerland & Ha D2 & $\begin{array}{l}11535 / 11540(\mathrm{SAM} \\
454)\end{array}$ & Historical Museum, Berne \\
\hline MA-200664 & $\begin{array}{l}\text { Finger ring } \\
\text { ('Schaukelring') }\end{array}$ & $\begin{array}{l}\text { Dürrnberg (Hallein), } \\
\text { Austria }\end{array}$ & Lt B (320-250 BC) & AR_1978_0077 & Keltenmuseum, Hallein \\
\hline MA-192493 & Applique & Rülzheim, Germany & Late Antique (5th c. AD) & E_2014_0100.021 & GDKE, Speyer \\
\hline MA-195126 & Cylindrical gold bead & Sulawesi, Indonesia & Unknown & None & Private collection \\
\hline MA-195133 & Cylindrical gold bead & Sulawesi, Indonesia & Unknown & None & Private collection \\
\hline MA-170001 & Daric, royal archer & Unknown & $420-375 \mathrm{BC}$ & $1.1 .4 \mathrm{a}$ & Private collection \\
\hline MA-197854 & Stater, Lysimachos & Unknown & $325-100 \mathrm{BC}$ & 1.5.6 & Private collection \\
\hline MA-197853 & 100 Litrae, Athena & Unknown & $305-289 \mathrm{BC}$ & 1.2 .10 & Private collection \\
\hline MA-197599 & Aureus, Augustus & Unknown & $8 / 7 \mathrm{BC}$ & Krö 510 & $\begin{array}{l}\text { Reiss-Engelhorn-Museen } \\
\text { Mannheim }\end{array}$ \\
\hline MA-197600 & Aureus, Tiberius & Unknown & Ante $16 \mathrm{AD}$ & Krö 511 & $\begin{array}{l}\text { Reiss-Engelhorn-Museen } \\
\text { Mannheim }\end{array}$ \\
\hline MA-197601 & Aureus, Nero & Unknown & $65 / 66 \mathrm{AD}$ & Krö 512 & $\begin{array}{l}\text { Reiss-Engelhorn-Museen } \\
\text { Mannheim }\end{array}$ \\
\hline MA-170018 & Aureus, Vespasianus & Unknown & $71 \mathrm{AD}$ & 3.2 .5 & Private collection \\
\hline MA-197857 & Solidus, Constantinus I. & Unknown & $324 / 325 \mathrm{AD}$ & 3.3 .1 & Private collection \\
\hline
\end{tabular}

15-mL standard vials). Each cement sample was mixed with 2 $\mathrm{mL}$ of concentrated $\mathrm{HCl}$ and left sealed overnight on a hot plate $\left(80^{\circ} \mathrm{C}\right)$. While still hot, the sample beakers were inserted into an ultrasonic bath for $10 \mathrm{~min}$ to ensure complete digestion. After cooling, the digestion solution was centrifuged, diluted and pipetted onto the first column (with $A G \circledR 1-X 8$ resin) as described above and prepared for conversion into the nitrate form.

For the $\mathrm{Cu}$ isotopic analysis, we took aliquots of the solutions of the gold and the cements prepared for Ag isotopic analyses. $\mathrm{Cu}$ separation was carried out with a chlorinebased anion exchange resin (AG MP-1, 100-200 mesh, BioRad Laboratories GmbH, Feldkirchen, Germany), which is widely used for the purification of transition elements. While for the metal samples, the removal of the two matrix elements $\mathrm{Au}$ and $\mathrm{Ag}$ was most important, the cement needed an additional purification from (earth-)alkali metals to avoid matrix effects and polyatomic interferences, especially on mass 63 due to the formation of ${ }^{23} \mathrm{Na}^{40} \mathrm{Ar}$. Aliquots containing approx. 3-5 $\mu \mathrm{g} \mathrm{Cu}$ were loaded on columns filled with $0.5 \mathrm{~mL} \mathrm{AG}$ MP-1. The addition of $1.5 \mathrm{~mL}$ of $11 \mathrm{~N} \mathrm{HCl}$ eluted most of the $\mathrm{Ag}$, (earth-)alkali elements and also $\mathrm{Ni}$, which have low affinities to the anion exchange resin. Afterwards, $\mathrm{Cu}$ was eluted with $4 \mathrm{~mL}$ of $2 \mathrm{~N} \mathrm{HCl}$ while Au was still retained on the resin. After $\mathrm{Cu}$ collection, the columns were rinsed with purified water. In order to ensure that no $\mathrm{Cu}$ loss occurred during the separation procedure, which would alter the copper isotopic composition (Maréchal et al. 1999), all steps were monitored by measuring the $\mathrm{Cu}$ concentrations in aliquots with Q-ICPMS (ICapQ, Thermo Fisher Scientific). This was achieved in two ways: Checking whether the 'matrix' step and the column wash were free of $\mathrm{Cu}$ as well as measuring the $\mathrm{Cu}$ concentration in the $\mathrm{Cu}$ fraction and comparing it with the amount initially loaded on the column, while simultaneously screening for interfering elements. In some cases, the $\mathrm{Cu}$ fraction still contained significant amounts of Ag so that the cleaning procedure had to be repeated. After yield tests were carried out, the $\mathrm{Cu}$ eluate was dried down and taken up with $0.3 \mathrm{~mol} \mathrm{~L}^{-1}$ $\mathrm{HNO}_{3}$ for isotopic measurement.

Although the quantitative recovery of $\mathrm{Cu}$ was verified for the whole procedure, an in-house standard $(\mathrm{Ag} 20 \mathrm{Cu})$ with known $\mathrm{Cu}$ isotopic composition was treated the same way. This $\mathrm{Ag}-\mathrm{Cu}-\mathrm{Au}$ metal was produced from pure metals (99.999\% Ag and Ag, $99.998 \%$ Au, Alfa Aesar) and the $\mathrm{Cu}$ isotopic composition in the $\mathrm{Cu}$ metal used for the preparation of the standard was analysed with and without column treatment as well as in the $\mathrm{Ag} 20 \mathrm{Cu}$ in-house standard.

The isotopic measurements were performed with a Thermo Scientific Neptune Plus multi-collector inductively coupled plasma mass spectrometer (MC-ICP-MS) at the CEZA. This instrument is equipped with nine faraday cups and three ion counters, among which L3-L1, Ax and H1-H3 are used to collect ${ }^{60} \mathrm{Ni},{ }^{61} \mathrm{Ni},{ }^{62} \mathrm{Ni},{ }^{63} \mathrm{Cu},{ }^{64} \mathrm{Ni},{ }^{65} \mathrm{Cu}$ and ${ }^{66} \mathrm{Zn}$ or ${ }^{105} \mathrm{Pd}$, ${ }^{106} \mathrm{Pd},{ }^{107} \mathrm{Ag},{ }^{108} \mathrm{Pd},{ }^{109} \mathrm{Ag},{ }^{110} \mathrm{Pd}$ and ${ }^{111} \mathrm{Cd}$, respectively. $\mathrm{Zn}$ 
and $\mathrm{Cd}$ isotopes were measured in order to monitor potential isobaric interferences. The isotopic measurements for both systems followed a similar protocol. Sample solutions were introduced into the mass spectrometer through a self-aspirating PFA nebuliser and a cyclonic/Scott-type spray chamber (uptake rate $0.1 \mathrm{~mL} \mathrm{~min}{ }^{-1}$ ). Data was collected in static, low-resolution mode employing the blank-reference-blank-sample-blankreference sequence. Data for the reference solutions were collected in one block of ninety 8.4-second integrations per peak while runs of samples consisted of three blocks of fifty 8.4second integrations. After baseline and blank corrections performed online, raw data were copied into Excel spreadsheets to calculate the $\delta^{109} \mathrm{Ag}$ and $\delta^{65} \mathrm{Cu}$ values in the samples relative to the corresponding bracketing reference materials. The spreadsheets were used to check for isobaric contributions, to remove outliers ( $>2 \mathrm{~s}$ ) of the measured isotope ratios and to apply the mass bias correction using the exponential law (Russell et al. 1978; Baxter et al. 2006).

$\mathrm{Ag}$ isotope ratios were measured as described by Brügmann et al. (2019). Instrumental mass bias correction was performed by doping the sample solutions with a $\mathrm{Pd}$ reference solution (CertiPUR® Pd ICP standard, Merck, Darmstadt, Germany, traceable to NIST SRM 978a), and an internal normalisation of ${ }^{108} \mathrm{Pd} /{ }^{105} \mathrm{Pd}$ to a nominal value of 1.18899 (Kelly and Wasserburg 1978). $\delta^{109} \mathrm{Ag}$ data is reported in per mill $(\%)$ relative to the bracketing analyses of the internationally used NIST SRM 978a Ag isotope reference:

$\delta^{109} \mathrm{Ag}=\delta^{109} \mathrm{Ag} / \delta^{107} \mathrm{Ag}=\left[\frac{\left({ }^{109} \mathrm{Ag} /{ }^{107} \mathrm{Ag}\right)_{\text {sample }}}{\left({ }^{109} \mathrm{Ag} /{ }^{107} \mathrm{Ag}\right)_{\text {NIST SRM 978a }}}-1\right] \times 1000$

Repeated measurements of replicate dissolutions and chromatographic separations for NIST SRM 978a and CEZAg reference solutions yielded the combined analytical uncertainty $(2 \mathrm{~s})$ of better about $0.02 \%$ of the analytical method reported by Brügmann et al. (2019).

Instrumental mass bias correction of the $\mathrm{Cu}$ isotope ratios was achieved by adding a Ni reference solution (ROTI®Star, Nickel ICP Standard, Carl Roth GmbH + Co. KG, Karlsruhe, Germany) to the sample solutions and an internal normalisation of the ${ }^{62} \mathrm{Ni} /{ }^{60} \mathrm{Ni}$ ratio to 0.1386 (Gramlich et al. 1989). $\delta^{65} \mathrm{Cu}$ data is reported in per mill $(\%)$ relative to the bracketing analyses of the internationally used NIST SRM $976 \mathrm{Cu}$ isotope reference:

$\delta^{65} \mathrm{Cu}=\delta^{65} \mathrm{Cu} / \delta^{63} \mathrm{Cu}=\left[\frac{\left({ }^{65} \mathrm{Cu} /{ }^{63} \mathrm{Cu}\right)_{\text {sample }}}{\left({ }^{65} \mathrm{Cu} /{ }^{63} \mathrm{Cu}\right)_{\text {NIST SRM } 976}}-1\right] \times 1000$
The combined analytical uncertainty $(2 \mathrm{~s})$ of the analytical method is about $0.02 \%$ as determined by repetitive analyses of the ICP reference solution (single-element $\mathrm{Cu}$ standard, P/ N S4400-10M141, CPI International, Santa Rosa, USA) and reference materials of bronze (BAM 211, IARM-91D).

Isotopic values are given in $\Delta^{109} \mathrm{Ag}$ and $\Delta^{65} \mathrm{Cu}$ (both in $\%$ ) where statements about the fractionation between the starting material and the product are needed:

$\Delta^{109} \mathrm{Ag}=\delta^{109} \mathrm{Ag}$ product ${ }^{109} \mathrm{Ag}$ starting material

$\Delta^{65} \mathrm{Cu}=\delta^{65} \mathrm{C} u_{\text {product }}-\delta^{65} \mathrm{Cu}_{\text {starting material }}$

Positive values in $\Delta^{109} \mathrm{Ag}$ and $\Delta^{65} \mathrm{Cu}$ mean enrichment in the heavier isotopes ${ }^{109} \mathrm{Ag}$ and ${ }^{65} \mathrm{Cu}$, while with negative value enrichment in the lighter isotopes ${ }^{107} \mathrm{Ag}$ and ${ }^{63} \mathrm{Cu}$ is indicated.

\section{Results}

\section{Cementation experiments with $\mathrm{NaCl}$ (CM1)}

The Sulawesi gold bead (MA-195126) used as starting material for the cementation treatments in the $\mathrm{CM} 1$ test series was a silver-rich ternary gold alloy with $54.7 \% \mathrm{Ag}$ and $2.4 \% \mathrm{Cu}$ (Table 3). According to the diagram shown in Online Resource 1, the metal has a pale greenish-yellow or almost white colour (cf. Fig. 1a). After the first cementation step (CM1a), the colour of the gold changed to a warm, more yellowish tone (Fig. 2, first row left), which was accompanied by a mass loss of $46 \%$ determined on the as-cemented metal (MA-195828). After rinsing in ethanol and re-melting the gold (MA-195829), a further $11 \%$ of the mass was lost, most likely due to the removal of reaction products in the form of particles and vapour. Examination of the as-cemented sample MA195828 with SEM-EDX revealed the typical porous microstructure of cemented gold with residues of $\mathrm{CuCl}_{2}$ in the pores and on the surface, but no $\mathrm{AgCl}$ was detected (Fig. 2, first-row middle). The Ag content at the surface of MA-195828 was $5.3 \%$, but after homogenisation (re-melting and hammering), the averaged Ag content in the gold foil (MA-195829) was somewhat higher with $6.2 \%$ (Table 3; Online Resource 2). Thus, depletion of Ag was more effective at the surface than inside the gold foil, as also demonstrated by LA-ICP-MS depth profiles (Fig. 2, bottom). Surprisingly, the reverse was observed for $\mathrm{Cu}$, because the concentration in the re-melted gold $(0.12 \%)$ was lower than that at the surface $(0.22 \%$; Table 3; Online Resource 2). The higher $\mathrm{Cu}$ content of the latter might be explained by the presence of residual $\mathrm{CuCl}_{2}$ on the surface and in the pores, as shown by the SEM-EDX analyses, and its conversion into the metal phase during melting under reducing conditions. 
Compared with the starting material, $88.7 \%$ of the $\mathrm{Ag}$ and $94.8 \%$ of the $\mathrm{Cu}$ were removed during the first cementation step (Table 3). This high loss of the main components had an impact on the $\mathrm{Ag}$ and $\mathrm{Cu}$ isotopic composition in the gold. $\delta^{109} \mathrm{Ag}$ increased from originally $-0.03 \pm 0.01 \%$ o towards a heavier composition of $0.41 \pm 0.03 \%$ in the purified gold, while, surprisingly, the $\delta^{65} \mathrm{Cu}$ value decreased from $0.28 \pm$ $0.03 \%$ in the starting gold alloy to $-0.25 \pm 0.05 \%$ in the cemented metal. Hence, a fractionation of the $\mathrm{Ag}$ isotopes of $\Delta^{109} \mathrm{Ag}=0.43 \%$ and the $\mathrm{Cu}$ isotopes of $\Delta{ }^{65} \mathrm{Cu}=-0.53 \%$ o was observed (Fig. 3; Table 3). There was furthermore a shift of the $\mathrm{Cu}$ isotopes in the cement towards lighter compositions relative to the metal, namely $\delta^{65} \mathrm{Cu}=-0.39 \pm 0.47 \%$. However, its $\mathrm{Ag}$ isotopic composition $\delta^{109} \mathrm{Ag}$ of $-0.03 \pm$ $0.002 \%$ is identical with that of the starting gold alloy within analytical errors (Table 3).

During the second cementation step (CM1b), the Ag and $\mathrm{Cu}$ contents in the gold were further reduced by 95.2 and $98.4 \%$ in total, compared with the original gold bead. In the re-melted metal (MA-195832), the Ag content was still 2.6\%, whereas the $\mathrm{Cu}$ content was very low with $370 \mathrm{\mu g} \mathrm{g}^{-1}$. On top of the yellow surface of the as-cemented gold alloy (MA195831), a high content of $\mathrm{Fe}$ in the form of a reddishbrown tarnish was present after the reaction (Fig. 2, second row left; Online Resource 2) that could easily be removed with ethanol. It was identified as ferric oxide $\left(\mathrm{Fe}_{2} \mathrm{O}_{3}\right)$ by SEM-EDX, which settled on top of residual $\mathrm{NaCl}$ (Fig. 2, second-row middle). The presence of the latter might be an explanation for the simple removal of the insoluble ferric oxide from the surface since the dissolution of $\mathrm{NaCl}$ automatically detaches $\mathrm{Fe}_{2} \mathrm{O}_{3}$. The additional depletion of $\mathrm{Ag}$ and $\mathrm{Cu}$ enhanced the fractionation of isotopes in the residual gold to $\Delta^{109} \mathrm{Ag}=3.3 \%$ and $\Delta^{65} \mathrm{Cu}=5.6 \%$. The latter value is remarkable as it indicates a fractionation effect opposite to the first cementation step. Whereas the $\mathrm{Cu}$ isotopes were forced towards a lighter composition in the first step relative to the original gold $\left(\delta^{65} \mathrm{Cu}=0.28\right.$ vs. $-0.25 \%$ o), they became isotopically heavier during the second treatment $\left(\delta^{65} \mathrm{Cu}=-\right.$ 0.25 vs. $5.6 \%$ o). Thus, during the second cementation step, $\mathrm{Cu}$ follows the fractionation behaviour of Ag (Fig. 3).

The third and final cementation step CM1c (Fig. 2, third row left) finished with even lower $\mathrm{Ag}$ and $\mathrm{Cu}$ concentrations in the gold with $0.57 \% \mathrm{Ag}$ and $120 \mu \mathrm{g} \mathrm{g}^{-1} \mathrm{Cu}$. Compared to the initial gold alloy, the $\mathrm{Ag}$ content was reduced in total by $99 \%$ and the $\mathrm{Cu}$ content by $99.5 \%$ during the three-stage cementation process. The $\delta^{109} \mathrm{Ag}$ and $\delta^{65} \mathrm{Cu}$ values rose to $7.5 \pm 0.02 \%$ and $11.6 \pm 0.03 \%$ o, respectively, which means an extreme fractionation of $\Delta^{109} \mathrm{Ag}=7.6 \%$ and $\Delta^{65} \mathrm{Cu}=11.3$ \%o (Fig. 3; Table 3).

During the course of the experimental series CM1, the initial gold alloy as well as each intermediate product were also analysed for their trace element concentrations with LA-QICP-MS using the time-resolved mode for depth-profiling, but only the data from the re-melted and homogenised samples is used for interpretation. The results are presented in Table 4 (a complete compilation can be found in Online Resource 2). Not all platinum group elements (PGE) were present in detectable concentrations: $\mathrm{Ru}$ and Os were below the method limit of detection of $1 \mu \mathrm{g} \mathrm{g}^{-1}$. During the individual cementation steps, $\mathrm{Rh}$ contents varied from 0.18 to $0.27 \mu \mathrm{g} \mathrm{g}^{-1}, \mathrm{Pd}$ from 41 to $87 \mu \mathrm{g} \mathrm{g}^{-1}$, Ir from 0.70 to $2.33 \mu \mathrm{g} \mathrm{g}^{-1}$ and Pt from 10 to $18 \mu \mathrm{g} \mathrm{g}^{-1}$. The observed
Table $3 \mathrm{Ag}$ and $\mathrm{Cu}$ contents (mass \%) and isotopic values (\%o) determined on samples of the original and cemented gold as well as on the cement of the CM1 a step. Also indicated are the losses of $\mathrm{Ag}$ and $\mathrm{Cu}$ (mass \%) during the respective cementation steps and the overall losses or cumulative losses. In addition, the data of samples $\mathrm{Z} 1$ and $\mathrm{Z} 3$ from the study of Wunderlich et al. (2014) are provided along with the $\mathrm{Ag}$ and $\mathrm{Cu}$ isotope fractionation $\delta^{109} \mathrm{Ag}$ and $\delta^{65} \mathrm{Cu}$ (in \%o) relative to the original gold. n.a. means not analysed (data: G. Brügmann, N. Lockhoff)

\begin{tabular}{|c|c|c|c|c|c|c|c|c|c|c|c|c|c|}
\hline Experiment & Lab. no. & $\mathrm{Ag}$ & Loss Ag & Loss $\mathrm{Ag}_{\text {cumulative }}$ & $\delta^{109} \mathrm{Ag}$ & $2 \mathrm{SD}$ & $\Delta^{109} \mathrm{Ag}$ & $\mathrm{Cu}$ & Loss $\mathrm{Cu}$ & Loss $\mathrm{Cu}_{\text {cumulative }}$ & $\delta^{65} \mathrm{Cu}$ & $2 \mathrm{SD}$ & $\Delta^{65} \mathrm{Cu}$ \\
\hline CM1 & MA-195126 & 54.7 & - & - & -0.028 & 0.010 & - & 2.35 & - & - & 0.28 & 0.03 & - \\
\hline CM1a & MA-195828 & 5.26 & - & - & 0.200 & 0.010 & - & 0.22 & - & - & 0.22 & 0.03 & - \\
\hline CM1a & MA-195829 & 6.16 & 88.7 & 88.7 & 0.405 & 0.028 & 0.433 & 0.12 & 94.8 & 94.8 & -0.25 & 0.05 & -0.53 \\
\hline CM1a & MA-195830 & $2.73 *$ & - & - & -0.025 & 0.002 & 0.003 & $0.44 *$ & - & - & -0.39 & 0.47 & -0.67 \\
\hline CM1b & MA-195831 & 0.16 & - & - & 3.53 & 0.025 & - & 0.002 & - & - & 6.76 & 0.01 & - \\
\hline CM1b & MA-195832 & 2.60 & 57.8 & 95.2 & 3.22 & 0.009 & 3.25 & 0.037 & 69.7 & 98.4 & 5.60 & 0.01 & 5.32 \\
\hline CM1b & MA-195833 & - & - & - & n.a. & - & - & - & - & - & n.a. & - & - \\
\hline CM1c & MA-195834 & 0.10 & - & - & 10.07 & 0.072 & - & 0.002 & - & - & 19.24 & 0.05 & - \\
\hline CM1c & MA-195835 & 0.57 & 78.0 & 99.0 & 7.52 & 0.018 & 7.55 & 0.012 & 67.6 & 99.5 & 11.56 & 0.03 & 11.28 \\
\hline CM1c & MA-195836 & - & - & - & n.a. & - & - & - & - & - & n.a. & - & - \\
\hline $\mathrm{Z} 1$ & MA-135432 & 17.1 & - & - & 0.070 & 0.034 & - & 0.29 & - & - & n.a. & - & - \\
\hline $\mathrm{Z3}$ & MA-135434 & 0.61 & 96.4 & 96.4 & 4.38 & 0.004 & 4.31 & 0.012 & 95.9 & 95.9 & n.a. & - & - \\
\hline
\end{tabular}

Note: Values tagged by an asterisk (*) were determined by SEM-EDX by normalising the chemical components to $100 \%$ 

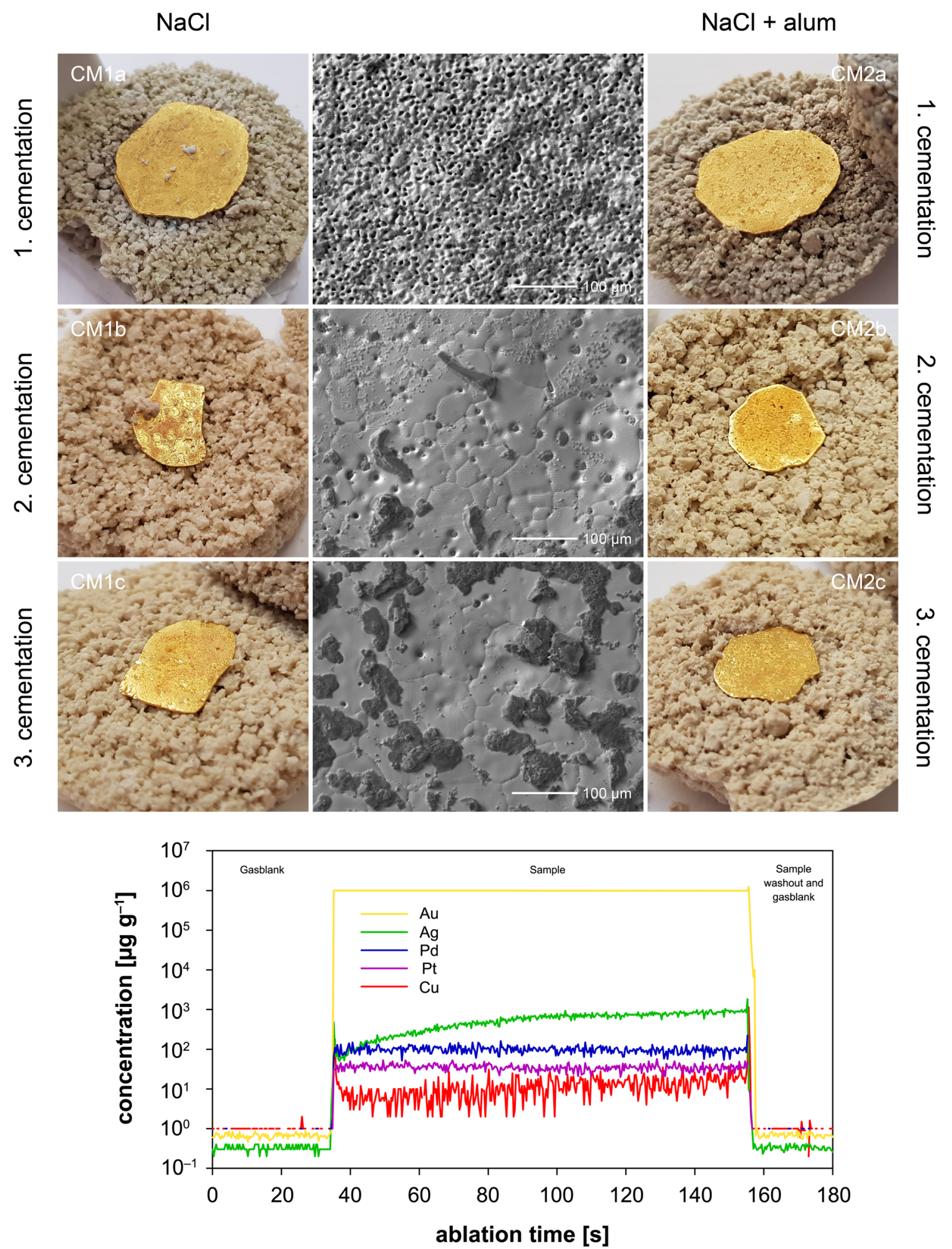

Fig. 2 Results of the CM1 (left panel) and CM2 (right panel) cementation experiments. Secondary electron images from the SEM examination of the resulting gold foils are shown in the central panel and apply to both

depletion with respect to the starting gold was low. Other trace element concentrations, like $\mathrm{Mn}, \mathrm{Fe}, \mathrm{Ni}, \mathrm{Zn}, \mathrm{Sn}, \mathrm{Sb}, \mathrm{Pb}$ and $\mathrm{Bi}$, varied from the low microgram per gram range to several test series. Below a depth profile of sample MA-195843 can be seen as obtained from LA-ICP-QMS (figure: D. Berger, N. Lockhoff)

hundred microgram per gram, and most of them became only slightly depleted except for $\mathrm{Pb}$ that shows enrichment (Table 4). 

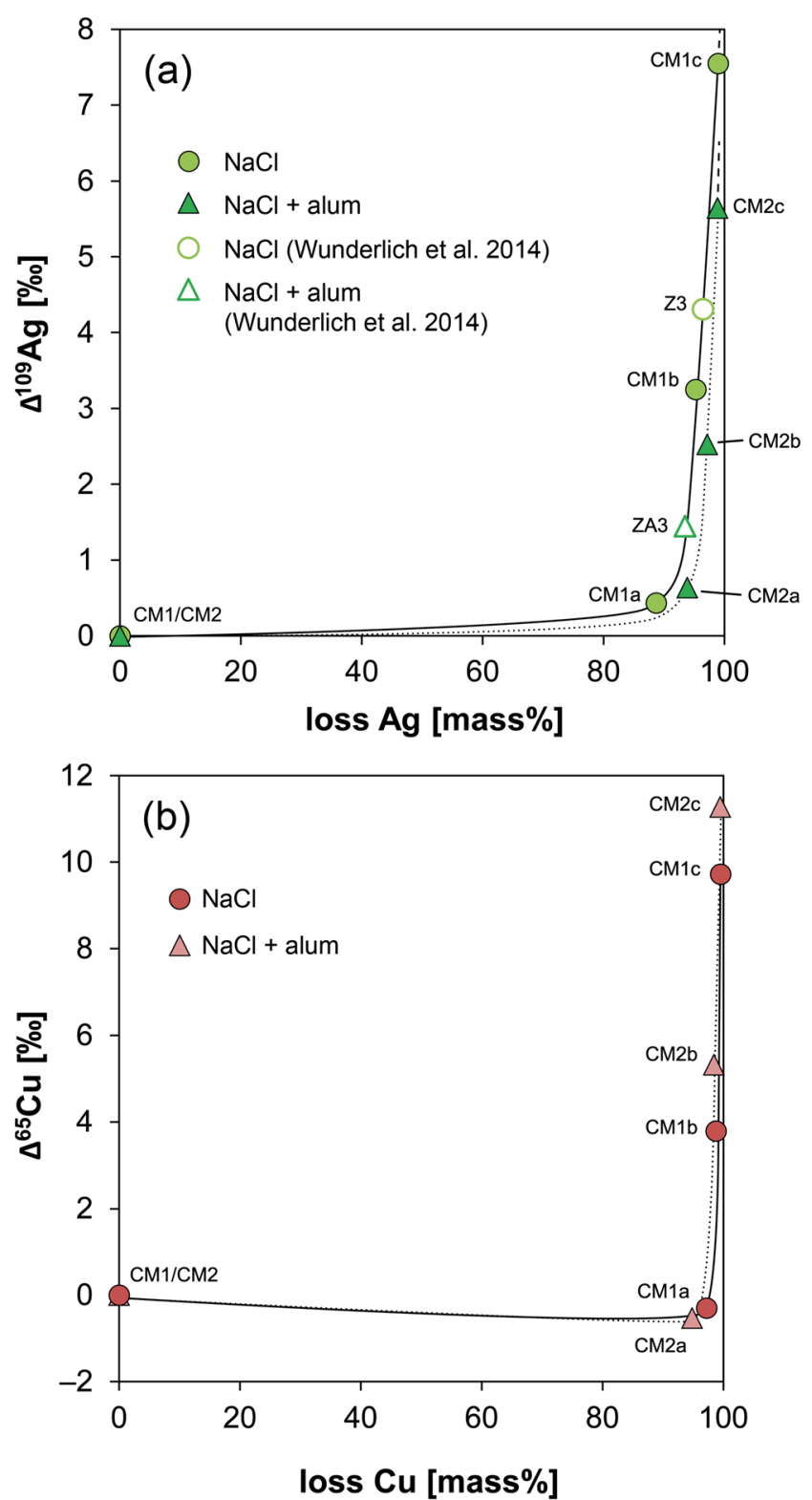

Fig. 3 Fractionation $\Delta^{109} \mathrm{Ag}$ (in \%o) and $\Delta^{65} \mathrm{Cu}$ (in \%o) of the cemented and re-melted samples from the $\mathrm{CM} 1(\mathrm{NaCl})$ and $\mathrm{CM} 2(\mathrm{NaCl}+$ alum) test series (including the samples of Wunderlich et al. 2014) relative to the original gold alloys and depending on the loss of $\mathrm{Ag}$ or $\mathrm{Cu}$ from the starting material. The course of fractionation is indicated by the solid (CM1) and dotted lines (CM2). Standard deviations (2SD) are smaller than the symbols (diagram: D. Berger, data: G. Brügmann, N. Lockhoff)

\section{Cementation experiments with $\mathrm{NaCl}$ and alum (CM2)}

The CM2 cementation experiments used a cement containing $\mathrm{NaCl}$ and alum and yielded similar results as the test series using $\mathrm{NaCl}$ alone (Fig. 2). While the gold colour became gradually more yellow during the experiments (Online Resource 1), the Ag content stepwise decreased from $55 \%$ in the original gold bead to $3.4 \%$ (MA-195838), $1.6 \%$ (MA195841 ) and $0.62 \%$ (MA-195844) in the homogenised metals (Table 5). $\mathrm{Cu}$ behaved similarly, and the initial concentration of $3.1 \%$ decreased systematically with each step from $860 \mu \mathrm{g}$ $\mathrm{g}^{-1}$ (MA-195838), $390 \mu \mathrm{g} \mathrm{g}^{-1}$ (MA-195841) to $150 \mu \mathrm{g} \mathrm{g}^{-1}$ (MA-195844). Compared with the first cementation step of the CM1a test series, the lower $\mathrm{Ag}$ and $\mathrm{Cu}$ contents of CM2a indicate a more efficient treatment. During the following two cementation steps, however, comparatively less $\mathrm{Cu}$ and $\mathrm{Ag}$ was removed which finally led to total loss of $\mathrm{Ag}$ and $\mathrm{Cu}$ of 98.9 and $99.5 \%$, respectively, similar to that in the CM1 experiment (Table 5; Online Resource 2). The Ag isotopic composition of originally $\delta^{109} \mathrm{Ag}=0.10 \pm 0.04 \%$ was again driven to heavier values during the individual experiments with a fractionation of $\Delta^{109} \mathrm{Ag}=0.64 \%$ (MA-195838), $2.52 \%$ (MA-195841) and $5.6 \%$ (MA-195844) (Fig. 3a). $\Delta^{65} \mathrm{Cu}$ of the first step was as negative as in CM1a by $-0.30 \%$ o (MA-195838), thus again lighter than the initial gold alloy $\left(\delta^{65} \mathrm{Cu}=0.17 \pm 0.01 \%\right.$ o $)$. As with the other experiment, the fractionation reversed during the next two cementation steps giving fractionation values of $\Delta^{65} \mathrm{Cu}=3.8 \%$ o (MA-195841) for the second and 9.7\%o (MA-195844) for the third treatment (Fig. 3b; Table 5). In contrast to the experiment $\mathrm{CM} 1$, the $\mathrm{Ag}$ isotopic composition of the cement after step one (MA-195839) is lighter than in the original metal $\left(\Delta^{109} \mathrm{Ag}=-0.085 \%\right.$ ) as well as its $\mathrm{Cu}$ isotopic composition $\left(\Delta^{65} \mathrm{Cu}=-0.24 \%\right.$ ).

In the $\mathrm{CM} 2$ products, the trace elements $\mathrm{Ru}$ and Os were also not detected. Rh concentrations ranged from 0.14 to $0.30 \mu \mathrm{g} \mathrm{g}^{-1}$, Pd from 33 to $80 \mu \mathrm{g} \mathrm{g}^{-1}$, Ir from 0.60 to $1.11 \mu \mathrm{g} \mathrm{g}^{-1}$ and Pt from 12 to $26 \mu \mathrm{g} \mathrm{g}^{-1}$. While Pt and Pd behaved relatively stable during the different cementation steps, $\mathrm{Rh}$ and Ir indicated depletion with continuing reaction (Table 4; a complete compilation of data can be found in Online Resource 2). The other trace elements were again present from the low microgram per gram range to several hundred micrograms per gram. Similar to CM1, most of them show slight depletion except $\mathrm{Sb}$ and $\mathrm{Bi}$ which were effectively removed from the gold (Table 4).

\section{Cementation experiments of Wunderlich et al. (2014)}

We also analysed the cemented sample Z3 (MA-135434) of Wunderlich et al.'s (2014) common salt cementation experiment (first cementation step). In comparison to the starting gold-silver alloy Z1 (MA-135432) with $17.1 \% \mathrm{Ag}$, the refined gold had lost $96.4 \%$ of the Ag resulting in $0.61 \%$. This was accompanied by an increase in $\delta^{109} \mathrm{Ag}$ from $0.07 \pm$ $0.03 \%$ to $4.4 \pm 0.004 \%$ and a fractionation of $\Delta^{109} \mathrm{Ag}=$ $4.3 \%$ (Fig. 3a; Table 3). The $\mathrm{Cu}$ concentration was reduced by $95.9 \%$, but the $\mathrm{Cu}$ isotopic composition was not determined. The fractionation of the $\mathrm{Ag}$ isotopes in Wunderlich et al.'s sample follows the trend of our experimental series CM1 (Fig. 3a).

Wunderlich et al. (2014) also carried out an experiment with $\mathrm{NaCl}$ and impure alum. Their samples ZA1 (starting gold 


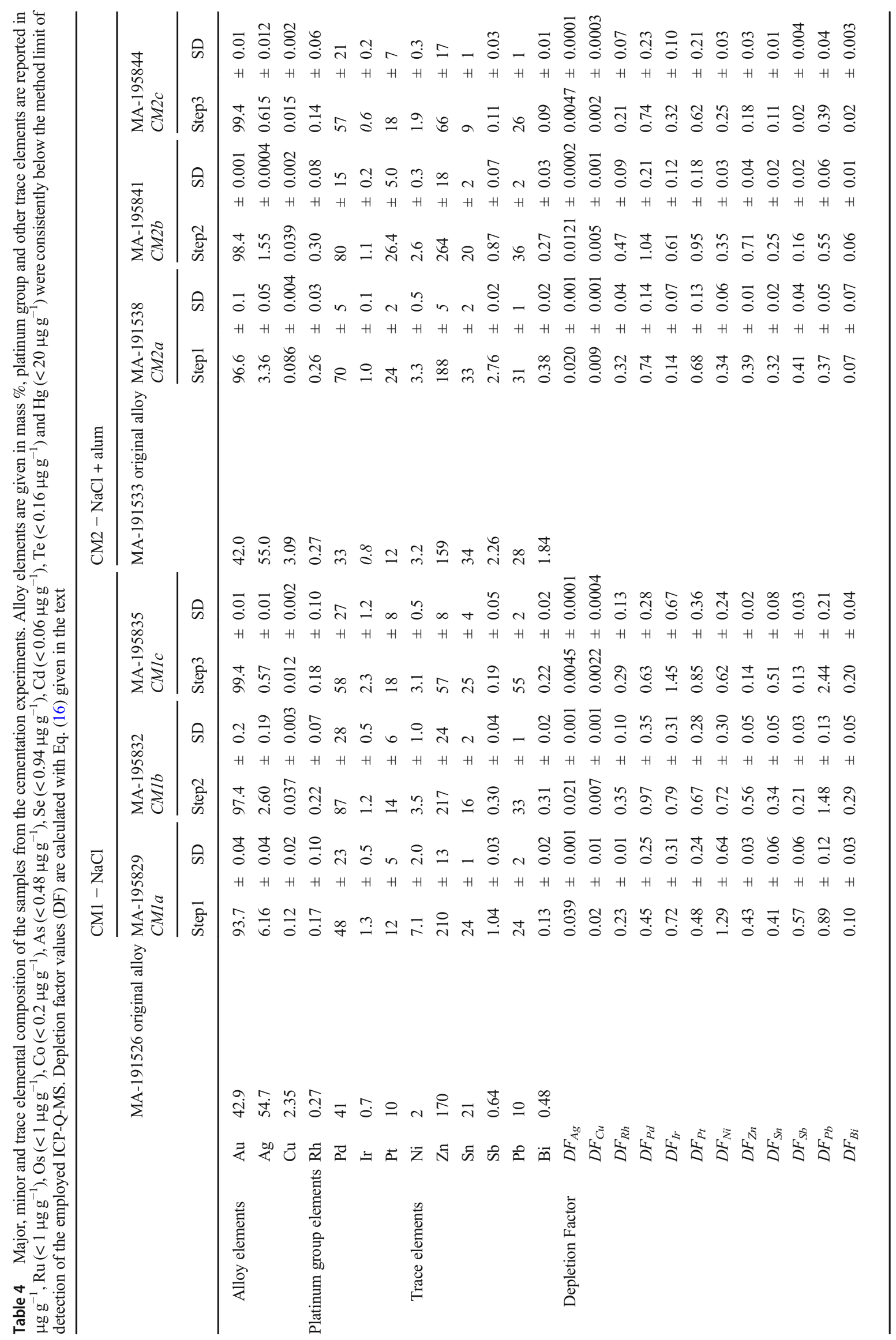


Table $5 \mathrm{Ag}$ and $\mathrm{Cu}$ contents (mass \%) and isotopic values (\%o) determined on samples of the original and cemented gold as well as on the cement of the CM2a step. Also indicated are the losses of $\mathrm{Ag}$ and $\mathrm{Cu}$ (mass \%) during the respective cementation steps and the overall losses or cumulative losses. In addition, the data of samples ZA1 and ZA3 from the study of Wunderlich et al. (2014) are provided along with the $\mathrm{Ag}$ and $\mathrm{Cu}$ isotope fractionation $\delta^{109} \mathrm{Ag}$ and $\delta^{65} \mathrm{Cu}$ (in \%o) relative to the original gold. n.a. means not analysed (data: G. Brügmann, N. Lockhoff)

\begin{tabular}{|c|c|c|c|c|c|c|c|c|c|c|c|c|c|}
\hline Experiment & Lab. no. & $\mathrm{Ag}$ & loss Ag & loss $A g_{\text {cumulative }}$ & $\delta^{109} \mathrm{Ag}$ & $2 \mathrm{SD}$ & $\Delta^{109} \mathrm{Ag}$ & $\mathrm{Cu}$ & loss $\mathrm{Cu}$ & loss $\mathrm{Cu}_{\text {cumulative }}$ & $\delta^{65} \mathrm{Cu}$ & $2 \mathrm{SD}$ & $\Delta^{65} \mathrm{Cu}$ \\
\hline $\mathrm{CM} 2$ & MA-195133 & 55.0 & - & - & 0.095 & 0.036 & - & 3.09 & - & - & 0.17 & 0.01 & - \\
\hline $\mathrm{CM} 2 \mathrm{a}$ & MA-195837 & 3.92 & - & - & 0.576 & 0.003 & - & 0.21 & - & - & 0.21 & 0.01 & - \\
\hline $\mathrm{CM} 2 \mathrm{a}$ & MA-195838 & 3.36 & 93.9 & 93.9 & 0.731 & 0.048 & 0.636 & 0.086 & 97.2 & 97.2 & -0.13 & 0.01 & -0.30 \\
\hline $\mathrm{CM} 2 \mathrm{a}$ & MA-195839 & $3.05^{*}$ & - & - & 0.010 & 0.020 & -0.085 & $0.32 *$ & - & - & -0.07 & 0.21 & -0.24 \\
\hline $\mathrm{CM} 2 \mathrm{~b}$ & MA-195840 & 0.13 & - & - & 2.48 & 0.01 & - & 0.003 & - & - & 4.96 & 0.01 & - \\
\hline $\mathrm{CM} 2 \mathrm{~b}$ & MA-195841 & 1.55 & 53.9 & 97.2 & 2.62 & 0.003 & 2.52 & 0.039 & 55.2 & 98.8 & 3.96 & 0.01 & 3.79 \\
\hline $\mathrm{CM} 2 \mathrm{~b}$ & MA-195842 & - & - & - & n.a. & - & - & - & - & - & n.a. & - & - \\
\hline $\mathrm{CM} 2 \mathrm{c}$ & MA-195843 & 0.08 & - & - & 10.29 & 0.01 & - & 0.002 & - & - & 14.31 & 0.02 & - \\
\hline $\mathrm{CM} 2 \mathrm{c}$ & MA-195844 & 0.62 & 60.3 & 98.9 & 5.74 & 0.01 & 5.64 & 0.015 & 60.3 & 99.5 & 9.88 & 0.02 & 9.71 \\
\hline $\mathrm{CM} 2 \mathrm{c}$ & MA-195845 & - & - & - & n.a. & - & - & - & - & - & n.a. & - & - \\
\hline ZA1 & MA-140384 & 20.9 & - & - & 0.157 & 0.074 & & 0.48 & - & - & n.a. & - & - \\
\hline ZA3 & MA-140386 & 1.36 & 93.5 & 93.5 & 1.60 & 0.06 & 1.45 & 0.0085 & 98.2 & 98.2 & n.a. & - & - \\
\hline
\end{tabular}

Note: Values tagged by an asterisk (*) were determined by SEM-EDX by normalising the chemical components to $100 \%$

alloy) and ZA3 (first cementation step) were also re-analysed. During the first cementation step, $93.5 \%$ of $\mathrm{Ag}$ and $98.2 \%$ of $\mathrm{Cu}$ were removed from the starting gold ZA1 (MA-140384). $\mathrm{Ag}$ and $\mathrm{Cu}$ contents dropped from 20.9 and $0.48 \%$ in ZA1 to 1.36 and $85 \mathrm{\mu g} \mathrm{g}^{-1}$ in the refined gold ZA3 (MA-140386) (Table 5). $\mathrm{Cu}$ isotope ratios were not determined, but $\mathrm{Ag}$ exhibits a very high fractionation of $\Delta^{109} \mathrm{Ag}=1.5 \%$ with $\delta^{109} \mathrm{Ag}=0.16 \pm 0.07 \%$ in ZA1 and $1.6 \pm 0.06 \%$ in ZA3. This fractionation aligns perfectly with that of CM1, whereas there is a deviation from the curve of the respective experiments CM2 with alum (Fig. 3a).

\section{Chemical and isotopic systematics of the gold artefacts}

All gold coins listed in Table 2 and used as the artefact group of possibly parted gold were chemically characterised using LA-Q-ICP-MS. Ag concentrations revealed only a limited range from 0.12 to $3.6 \%$, and $\mathrm{Cu}$ contents were inconsistently low with values from 8 to $2100 \mu \mathrm{g} \mathrm{g}^{-1}$ (Table 6; Online Resource 3). Trace element contents varied considerably from coin to coin, but often only $\mathrm{Fe}, \mathrm{Zn}, \mathrm{Sn}, \mathrm{Sb}, \mathrm{Pb}, \mathrm{Bi}$ and PGE were present at detectable concentrations. The isotopic composition of $\mathrm{Ag}$ showed a variation from 0.03 to $2.5 \% \circ \delta^{109} \mathrm{Ag}$ and there is a trend where the gold with isotopically heavier $\mathrm{Ag}$ isotopic composition has lower Ag concentrations (Fig. 4a). $\mathrm{Cu}$ isotopes were not determined due to the low $\mathrm{Cu}$ concentrations and small sample sizes.

Large differences in the major, minor and trace element abundances were observed in the other gold artefacts, which originally served as a reference group of un-refined gold (Table 6; Online Resource 3). The highest Ag and $\mathrm{Cu}$ contents were found in the Sulawesi beads (see above), followed by the Nebra Sky Disc (FG-030531) with 20.9\% Ag and 0.39\% Cu (data from Schmiderer 2008). The bracelet and necklace from Mühleberg-Allenlüften (MA-197619 and MA-197620) contained similarly high $\mathrm{Cu}$ concentrations as the disc, but their Ag contents are lower at 11.1 and $11.7 \%$ respectively. The lowest Ag contents were observed in the gold applique from Rülzheim (MA-192493) and the golden finger ring from the Dürrnberg (MA-200664), which contained 3.2 and $2.5 \%$ Ag besides 0.15 and $0.46 \% \mathrm{Cu}$. These objects had also the heaviest Ag isotopic composition of the archaeologically recovered objects with $\delta^{109} \mathrm{Ag}=0.54 \pm 0.1 \%$ for the applique and $1.87 \pm 0.02 \%$ for the ring. The remaining objects displayed $\mathrm{Ag}$ isotope ratios ranging from -0.03 to $0.17 \%$ o (Fig. 4a; Table 6). Interestingly, the two artefacts from Mühleberg-Allenlüften were almost identical in their Ag isotopic signatures and chemical compositions (Table 6; Online Resource 3). Moreover, these two and the other archaeologically recovered artefacts establish an 'exponential' trend line with the coins (Fig. 4a), from which only the finger ring and one gold coin slightly deviate (MA-197853).

\section{Discussion}

The results of our experiments reveal that the isotopes of $\mathrm{Cu}$ and Ag become extremely fractionated during the parting of gold-silver-copper alloys and thus could represent a distinct fingerprint of this process. In the following discussion, the chemical reactions and the efficiency of the process will be described and explanations of possible fractionation 
Table 6 Chemical (mass \%) and isotopic data $(\%$ ) of the gold objects. The last column specifies the estimated Ag content (mass \%) of the original gold alloy for those objects which were most likely made from cemented gold. The approach is described in the text and in Fig. 4 (data: D. Berger, G. Brügmann, N. Lockhoff)

\begin{tabular}{lllllllll}
\hline Lab. no. & Object & $\mathrm{Ag}$ & $\mathrm{Cu}$ & $\delta^{109} \mathrm{Ag}$ & $2 \mathrm{SD}$ & $\delta^{65} \mathrm{Cu}$ & $2 \mathrm{SD}$ & $\mathrm{Ag}_{\text {initial }}$ \\
\hline FG-030531 & Sky Disc & 20.9 & 0.39 & 0.173 & 0.059 & n.a. & - & - \\
MA-197619 & Necklace & 11.1 & 0.34 & 0.150 & 0.020 & n.a. & - & - \\
MA-197620 & Bracelet & 11.7 & 0.26 & 0.160 & 0.010 & n.a. & - & - \\
MA-200664 & Finger ring & 2.54 & 0.46 & 1.87 & 0.02 & n.a. & - & $36.3-48.9$ \\
MA-192493 & Applique & 3.2 & 0.15 & 0.540 & 0.010 & n.a. & - & - \\
MA-195126 & Bead & 54.7 & 2.35 & -0.028 & 0.010 & 0.28 & 0.03 & - \\
MA-195133 & Bead & 55.0 & 3.09 & 0.095 & 0.036 & 0.17 & 0.01 & - \\
MA-170001 & Daric & 1.0 & 0.24 & 1.31 & 0.003 & n.a. & - & $9.4-17.5$ \\
MA-197854 & Stater & 1.71 & 0.168 & 0.850 & 0.010 & n.a. & - & $?-28.5$ \\
MA-197853 & 100 Litrae & 3.6 & 0.056 & 0.026 & 0.010 & n.a. & - & - \\
MA-197599 & Aureus & 0.12 & 0.0008 & 1.79 & 0.04 & n.a. & - & $1.6-2.3$ \\
MA-197600 & Aureus & 0.42 & 0.011 & 2.49 & 0.08 & n.a. & - & $6.9-9.1$ \\
MA-197601 & Aureus & 0.65 & 0.076 & 0.863 & 0.023 & n.a. & - & $?-10.8$ \\
MA-170018 & Aureus & 1.0 & 0.055 & 0.620 & 0.050 & n.a. & - & - \\
MA-197857 & Solidus & 2.29 & 0.21 & 0.068 & 0.001 & n.a. & - & - \\
\hline
\end{tabular}

mechanisms will be proposed. Finally, we will present examples of practical applications and their limitations.

\section{Mechanism of the cementation process}

In order to understand the cause of the pronounced element depletion and isotope fractionation effects, it is essential to recall the chemical reactions involved in cementation and the physical constraints controlling the effectiveness of the process. Craddock (2000b) and Celauro et al. (2017) provide the most comprehensive compilation of the reactions and consider the different materials used for parting (cf. Wunderlich et al. 2014). The basic reaction referred to by these authors is the pyrohydrolysis of $\mathrm{NaCl}$ in the presence of water and silica (or alumina) at high temperatures (see also Zhou et al. 2016):

$2 \mathrm{NaCl}+\mathrm{SiO}_{2}+\mathrm{H}_{2} \mathrm{O} \leftrightarrow \mathrm{Na}_{2} \mathrm{SiO}_{3}+\mathrm{HCl}$

The hydrogen chloride formed in this reaction was regarded as the active agent in the oxidation of $\mathrm{Ag}$ Wunderlich et al. (2014). In addition, it was proposed that gaseous chlorine could be the main active agent in the process (Bayley 1991; Craddock 2000b). This assumption is based on the observation that at high temperature, and in the presence of water, metal oxides such as the omnipresent $\mathrm{Fe}_{2} \mathrm{O}_{3}$, e.g. in the fired clay powder and the reaction vessel, react to $\mathrm{Fe}$ chlorides which promote the further breakdown of $\mathrm{HCl}$ to $\mathrm{Cl}_{2}$ (Craddock 2000b; Celauro et al. 2017):

$\mathrm{Fe}_{2} \mathrm{O}_{3}+6 \mathrm{HCl} \leftrightarrow 2 \mathrm{FeCl}_{3}+3 \mathrm{H}_{2} \mathrm{O}$

$$
\begin{aligned}
& 4 \mathrm{FeCl}_{3}+7 \mathrm{H}_{2} \mathrm{O} \leftrightarrow \mathrm{Fe}_{2} \mathrm{O}_{3}+\mathrm{FeOCl}+\mathrm{Fe}(\mathrm{OH})_{3} \\
& \quad+11 \mathrm{HCl} \\
& 2 \mathrm{FeCl}_{3} \leftrightarrow 2 \mathrm{FeCl}_{2}+\mathrm{Cl}_{2}
\end{aligned}
$$

The presence of ferric oxide on the surface of the gold foils at the end of the cementation (cf. Fig. 2; Online Resource 2) indicates that the above-formulated reactions had taken place during our experiments. They are also the reason why the cementation mixture is coloured slightly red where the gold was in contact with the silicates. The Fe may derive from the fired clay containing half a percent of it (Table 7). Ferric chloride is volatile at the experimental temperatures and is converted to oxide, when it gets into contact with the silicates present. Similar haematite encrustations have been observed on gold foils and in parting vessels from Sardis and in crucibles from Roman and mediaeval Britain (Bayley 1991; Geçkinli et al. 2000, 186).

However, besides chlorine, $\mathrm{FeCl}_{3}$ itself could have been an active agent in the attack on the Ag during our experiments. This is possible if we take into consideration the dry conditions that may have formed in the crucible after some time (Craddock 2000b). Normally, the used fuel such as wood provides enough moisture throughout the entire refining procedure (Bayley 1991; Craddock 2000b). In our case, no fuel but an electric furnace was employed so that after a while there was probably not enough water to continuously promote the production of $\mathrm{HCl}$ and $\mathrm{Cl}_{2}$ via formulas (6-8). If true, ferric chloride might have dominated refining as also speculated for the Sardis finds (Meeks 2000, 151). This could be one reason for the comparatively low Ag depletion during our 
cementation experiment compared to Celauro et al.'s (2017) (they recorded depletion of almost $99 \%$ Ag after the first step).

With regard to $\mathrm{Ag}$, the most important reaction is the oxidation of $\mathrm{Ag}$ on the surface of the gold alloy resulting in silver chloride $(\mathrm{AgCl})$. Depending on the active agent $\left(\mathrm{HCl}, \mathrm{Cl}_{2}\right.$, $\mathrm{FeCl}_{3}$ ), this occurs according to the following three reactions:

$2 \mathrm{Ag}+2 \mathrm{HCl}+\frac{1}{2} \mathrm{O}_{2} \leftrightarrow 2 \mathrm{AgCl}+\mathrm{H}_{2} \mathrm{O}$

$2 \mathrm{Ag}+\mathrm{Cl}_{2} \leftrightarrow 2 \mathrm{AgCl}$

or

$6 \mathrm{Ag}+2 \mathrm{FeCl}_{3}+\frac{3}{2} \mathrm{O}_{2} \leftrightarrow 6 \mathrm{AgCl}+\mathrm{Fe}_{2} \mathrm{O}_{3}$

The $\mathrm{Cu}$ in the gold reacts similarly under the highly oxidic conditions and basically forms cupric chloride $\left(\mathrm{CuCl}_{2}\right)$ :

$$
\begin{aligned}
& \mathrm{Cu}+2 \mathrm{HCl}+\frac{1}{2} \mathrm{O}_{2} \leftrightarrow \mathrm{CuCl}_{2}+\mathrm{H}_{2} \mathrm{O} \\
& \mathrm{Cu}+\mathrm{Cl}_{2} \leftrightarrow \mathrm{CuCl} \\
& 3 \mathrm{Cu}+2 \mathrm{FeCl}_{3}+\frac{3}{2} \mathrm{O}_{2} \leftrightarrow 3 \mathrm{CuCl}_{2}+\mathrm{Fe}_{2} \mathrm{O}_{3}
\end{aligned}
$$

Furthermore, $\mathrm{CuCl}_{2}$ is known to dissociate yielding cuprous chloride $(\mathrm{CuCl})$ and more chlorine:

$$
2 \mathrm{CuCl}_{2} \leftrightarrow 2 \mathrm{CuCl}+\mathrm{Cl}_{2}
$$

In the hot oxidising atmosphere, $\mathrm{CuCl}$ can react further (Hisham and Benson 1995; Craddock 2000b) so that the behaviour of $\mathrm{Cu}$ during the cementation is rather complex. This could be even more complicated when considering the sulphate in alum, which had been used in experiment CM2. In summary, elements occurring in the di- and trivalent states, such as $\mathrm{Fe}$ and $\mathrm{Cu}$, can promote the formation of chlorine gas to act as active agent; the univalent $\mathrm{Ag}$ and $\mathrm{Au}$, however, cannot trigger this reaction (Craddock 2000b).

For understanding the fractionation effects displayed by the $\mathrm{Cu}$ and $\mathrm{Ag}$ isotopic compositions, it is important to know which processes and which mineral, melt and vapour phases are involved and dominate the depletion process. Secondary electron images in Fig. 2 and in the literature (Meeks 2000; Geçkinli et al. 2000) show that the corrosive attack at the surface is primarily local, i.e. it occurs at weak spots (energy rich) where several crystals meet or crystal defects exist. A laminar propagation along grain boundaries is very rarely visible here, but it is the rule in the interior of the gold foil. At high temperature, gold itself is not inactive. In particular, the recrystallisation of the strongly deformed metal (after hammering the foils) occurs simultaneously with the oxidation of $\mathrm{Ag}$ and $\mathrm{Cu}$ and could initially hinder the propagation process of the acid attack towards the interior.
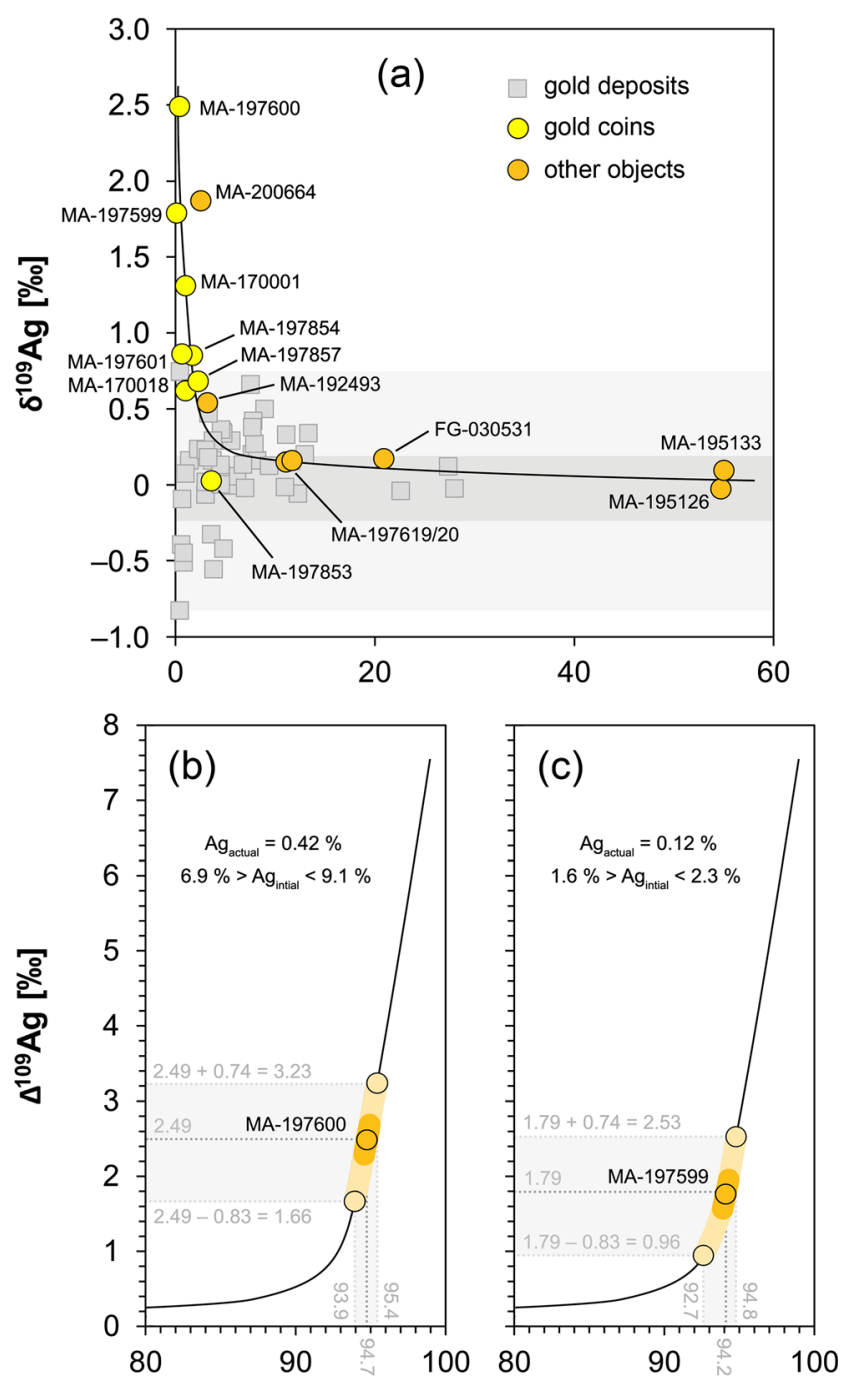

loss Ag [mass\%]

loss Ag [mass\%]

Fig. $4 \mathrm{Ag}$ isotopic composition and $\mathrm{Ag}$ contents of the examined gold artefacts and of primary and secondary gold deposits (literature data as referenced in Fig. 9). The light grey area represents the Ag isotopic variation in natural gold, while the medium grey bar represents the variation in silver coins (data from Desaulty et al. 2011; Desaulty and Albarède 2013; Albarède et al. 2016, 2020; Milot et al. 2021). Both areas only serve for comparative purposes. In $\mathbf{b}$ and $\mathbf{c}$, the measured $\mathrm{Ag}$ isotopic composition of two coins is used to estimate the Ag content of the original, uncemented gold $\left(\mathrm{Ag}_{\text {initial }}\right)$. This is achieved on the basis of the experimental results from the CM1 cementation test series (solid line) and the natural $\mathrm{Ag}$ isotopic variation in gold deposits (light orange line). The end members (light orange circles) are defined by the isotopically lightest $\left(\delta^{109} \mathrm{Ag}_{\text {artefact }}-0.83 \%\right)$ and heaviest $\left(\delta^{109} \mathrm{Ag}_{\text {artefact }}+0.74 \%\right)$ native gold ores (a). The orange circles represent the isotopic composition of the coins assuming an original $\delta^{109} \mathrm{Ag}_{\text {initial }}$ of 0 . Between these three circles, the original gold of the coin could have had any value with the most probable range indicated by the dark orange line (variation of $\mathrm{Ag}$ isotope ratios in silver objects; a). Standard deviations (2SD) are smaller than the symbols (diagrams: D. Berger, data: G. Brügmann, N. Lockhoff)

Nevertheless, a continuous exchange of the reaction products with the acids must be guaranteed; otherwise, the reaction would come to a standstill. This exchange most likely takes 
Table 7 Chemical composition of the cements from both test series and the used fired clay determined with SEM-EDX and normalised to $100 \%$. All values are given in mass \% (data: D. Berger)

\begin{tabular}{|c|c|c|c|c|c|c|c|c|c|c|c|c|c|c|}
\hline Experiment & Lab. no. & $\mathrm{O}$ & $\mathrm{Na}$ & $\mathrm{Mg}$ & $\mathrm{Al}$ & $\mathrm{Si}$ & S & $\mathrm{Cl}$ & $\mathrm{K}$ & $\mathrm{Ca}$ & $\mathrm{Ti}$ & $\mathrm{Fe}$ & $\mathrm{Cu}$ & $\mathrm{Ag}$ \\
\hline Fired clay & MA-196443 & 37.4 & 0.20 & 0.45 & 14.5 & 43.0 & & & 2.23 & 0.33 & 1.11 & 0.64 & & \\
\hline CM1a & MA-195830 & 33.2 & 13.4 & 0.19 & 5.7 & 15.4 & & 22.4 & 1.45 & 4.4 & 0.47 & 0.25 & 0.44 & 2.73 \\
\hline CM1b & MA-195833 & 36.6 & 12.9 & 0.20 & 4.5 & 12.6 & & 25.8 & 1.64 & 4.9 & 0.46 & 0.31 & & \\
\hline CM1c & MA-195836 & 31.2 & 14.2 & 0.16 & 5.3 & 14.5 & & 28.2 & 1.53 & 4.2 & 0.45 & 0.30 & & \\
\hline $\mathrm{CM} 2 \mathrm{a}$ & MA-195839 & 28.3 & 14.0 & 0.25 & 5.8 & 14.9 & 1.00 & 24.5 & 1.71 & 5.4 & 0.44 & 0.29 & 0.32 & 3.05 \\
\hline $\mathrm{CM} 2 \mathrm{~b}$ & MA-195842 & 32.8 & 12.5 & 0.10 & 5.6 & 15.5 & 1.02 & 24.9 & 1.82 & 5.0 & 0.44 & 0.34 & & \\
\hline $\mathrm{CM} 2 \mathrm{c}$ & MA-195845 & 27.2 & 14.3 & 0.27 & 6.4 & 16.3 & 1.25 & 26.6 & 2.08 & 4.9 & 0.47 & 0.27 & & \\
\hline
\end{tabular}

place predominantly via diffusion processes: Ag and $\mathrm{Cu}$ chlorides (and chlorides of trace elements) are transported outwards via grain and twin boundaries and are absorbed by the cement, while $\mathrm{Cl}_{2}$ and $\mathrm{FeCl}_{3}$ diffuse into the gold foil through the same routes to sustain the oxidation of both metals (Fig. 5). The progressive removal of the alloying elements from the crystal surface leads to the formation of porosity along the propagation paths. Within grains, diffusion of $\mathrm{Ag}$ and $\mathrm{Cu}$ through the crystal lattice of the gold dominates and results in further pores (Fig. 5). The concentration gradient between the Ag- and $\mathrm{Cu}$-rich cores and the depleted margins is likely the driving force which promotes the $\mathrm{Ag}$ and $\mathrm{Cu}$ depletion of the entire gold grains. Since the diffusion of $\mathrm{Ag}$ and $\mathrm{Cu}$ in the solid gold or along grain boundaries is slow (Pan and Balluffi 1982; Geçkinli et al. 2000), this could be a limiting and thus kinetic factor to the entire cementation process. Moreover, the recrystallisation and thus re-ordering of the gold may be of some significance as it can temporarily hinder the depletion reaction. Finally, a sustained supply of $\mathrm{NaCl}$ must be guaranteed until the end of the cementation procedure; otherwise, the basic reactions (Eq. (5)) will come to an end.

The physical conditions of the different reagents (solid, liquid or gaseous) also have an important influence on the effectiveness of the process. At temperatures above $800{ }^{\circ} \mathrm{C}$, $\mathrm{HCl}$ and $\mathrm{Cl}_{2}$ are gases. $\mathrm{CuCl}_{2}$ should be liquid at the working temperatures of $850{ }^{\circ} \mathrm{C}$ (melting point of $498{ }^{\circ} \mathrm{C}$ ), but it is possible that it partly evaporates far below its boiling point $\left(993{ }^{\circ} \mathrm{C}\right)$. In both the CM1a and CM2a experiments, a bluish glaze was observed inside of the lids indicating the presence of hydrated cupric chloride $\left(\mathrm{CuCl}_{2} \cdot 2 \mathrm{H}_{2} \mathrm{O}\right)$. The glaze also contained $\mathrm{Fe}$ and $\mathrm{Ag}$ as determined by qualitative XRF measurements in our laboratory. It resembles bluish remnants on archaeological ceramics (Bayley 1991; Bayley et al. 2008) and crucibles of other cementation experiments (Notton 1974).

The behaviour of $\mathrm{AgCl}$ is not well understood. Wunderlich et al. (2014) proposed that this phase is present as a melt. The low melting point of $455{ }^{\circ} \mathrm{C}$ supports this idea, and $\mathrm{AgCl}$ can be readily absorbed or slagged by the fired clay as indicated by the high Ag content in the cement of our experiments (Table 7). The boiling temperature of $\mathrm{AgCl}\left(1547^{\circ} \mathrm{C}\right)$ is much higher than the temperature during our experiments. Nevertheless, Bayley (1991), Geçkinli et al. (2000) and Craddock (2000b) assumed that $\mathrm{AgCl}$ behaves volatile. The presence of $\mathrm{Ag}$ in the sublimates at the lids of our reaction vessels would also support the presence of a volatile Ag phase. Thus, at least a small contribution of evaporation to the loss of silver has to be considered.

\section{Major and trace element distribution during the cementation process}

The results of our experiments confirm previous experimental investigations in that gold alloys can be effectively purified by the cementation process with common salt (Notton 1974; Craddock 2000b; Geçkinli et al. 2000; Wunderlich et al. 2014; Blet-Lemarquand et al. 2017; Celauro et al. 2017). As described above, the efficient removal of $\mathrm{Ag}$ and $\mathrm{Cu}$ is based on the formation of chlorides. However, the cementation should also affect other elements that can form chloride compounds, which can be mobilised and eventually removed from the gold. Measurable trace element concentrations in the studied gold alloys were $\mathrm{Ni}, \mathrm{Zn}, \mathrm{Sn}, \mathrm{Sb}, \mathrm{Pb}$ and $\mathrm{Bi}$ as well as the platinum group elements $\mathrm{Rh}, \mathrm{Ir}, \mathrm{Pd}$ and $\mathrm{Pt}$. In order to describe the extent of element depletion during the cementation process, the element to the gold concentration ratio of the starting material is compared to the corresponding ratios of the three cementation steps. For this purpose, a relative (inverse) depletion factor $D F$ is defined using the following equation:

$D F_{x}=\frac{X_{a}}{A u_{a}} / \frac{X_{\text {initial }}}{A u_{\text {initial }}}$

where $X$ is the concentration of the major or trace elements in microgram per gram, $A u$ is the concentration of the gold, while subscript $a$ refers to the specific cementation step and initial to the initial one. These values and the concentration data to calculate them are given in Table 4 (element 
Fig. 5 Schematic illustration of the principle reactions and processes during gold parting by cementation with $\mathrm{NaCl}$. It can be described most vividly in the words of Meeks (2000, p. 151):

'The cementation parting process involves surface chemical reactions and thermally activated solid-state diffusion within the metal. The chemical reaction between the silver [and copper; note of the authors] in the gold alloy and the active parting agents, most likely chlorine or ferric chloride released from the parting charge, occurs initially at the gold alloy surface but appears to progress quickly inwards along grain boundaries to form pathways which allow reactants to penetrate the core of the alloy. Diffusion gradients soon form between the silver-depleted [and copperdepleted; note of the authors] grain-boundary zones and the silver-rich [and copper-rich; note of the authors] core of the metal grains. As silver [and copper; note of the authors] is lost from the interior, an open sponge-like network forms, creating more reaction surfaces. [...] In this way, purification becomes a threedimensional process rather than simply just progressing from the exposed outer foil surfaces'. (illustration: D. Berger; caption text: from Meeks 2000, p. 151)

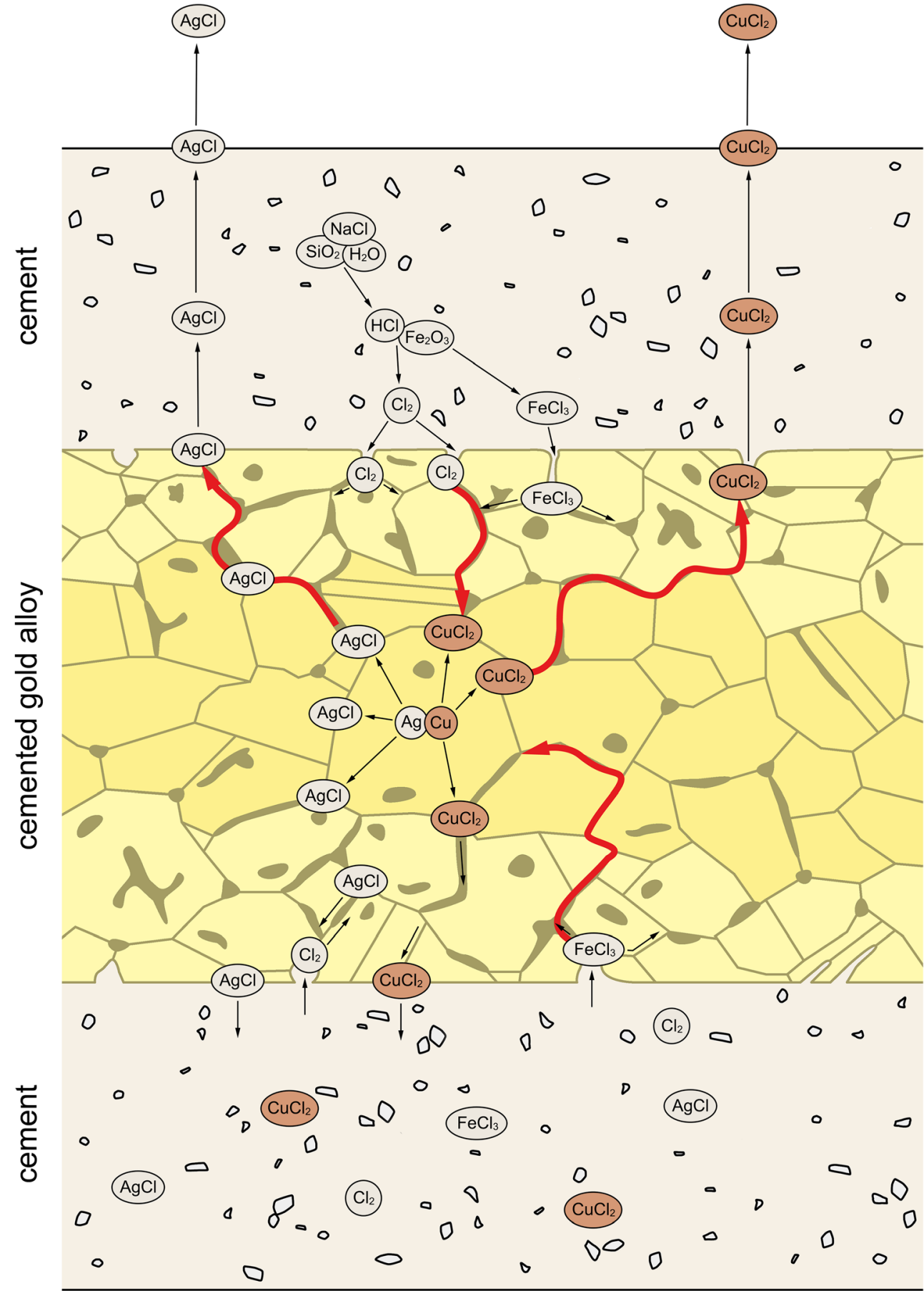

concentrations also compiled in Online Resource 2). A depletion factor of $\mathrm{DF}=1$ means that no depletion or enrichment (contamination) occurred and that the $\mathrm{X} / \mathrm{Au}$ ratio was constant during the respective step. Consequently, a depletion factor $\mathrm{DF}<1$ indicates depletion relative to $\mathrm{Au}$, while $\mathrm{DF}>1$ means a relative enrichment (or contamination).

In Figs. 6 and 7, DF values are illustrated. With the exception of $\mathrm{Pb}$, all trace elements became depleted during the course of the process relative to the initial composition. In contrast, $\mathrm{Pb}$ concentrations steadily increased in $\mathrm{CM} 1$ with a $\mathrm{DF}_{\mathrm{Pb}}$ of up to $2.44 \pm 0.21$, while this trend is not so obvious in the experiment CM2. Most likely, this effect was caused by contamination with $\mathrm{Pb}$, which has been added by the materials used for the experiment, for instance, the cementation mixture or the crucible. However, we did not check for the trace element composition of the used fired clay and the other reagents. Due to the very low $\mathrm{Pb}$ contents of the initial gold with less than $30 \mu \mathrm{g} \mathrm{g}^{-1}$ (Table 4), even very small amounts of $\mathrm{Pb}$ will affect the results. This is a very fundamental observation 
as it can severely limit the applicability of $\mathrm{Pb}$ isotope ratios in provenance studies of archaeological gold.

With a few exceptions, both experimental series show a similar behaviour of the various elements, although, at the end of all cementation steps, the experiments of CM2 with alum and salt tend to be slightly more effective. The strongest depletion was accomplished for the alloying elements, because $\mathrm{Ag}$ and $\mathrm{Cu}$ had the lowest $\mathrm{DF}$ of $\mathrm{DF}_{\mathrm{Ag}}=0.0045 \pm$ 0.0001 and $\mathrm{DF}_{\mathrm{Cu}}=0.0022 \pm 0.0004$ for $\mathrm{CM} 1$ and $\mathrm{DF}_{\mathrm{Ag}}=$ $0.0047 \pm 0.0001$ and $\mathrm{DF}_{\mathrm{Cu}}=0.0020 \pm 0.0003$ for $\mathrm{CM} 2$, respectively.

In the experiments of Wunderlich et al. (2014) and those of Celauro et al. (2017), the removal of Ag and $\mathrm{Cu}$ was even more effective than observed in our tests. Wunderlich and co-workers (2014) achieved a Ag depletion of $96 \%$ during the first cementation step using a cement with $\mathrm{NaCl}$, while Celauro et al. (2017, 189-192) even recorded a loss of more than $99 \%$ when using $\mathrm{NaCl}$. In comparison, Celauro et al. (2017) used a 1:1 mixture of $\mathrm{NaCl}$ and brick dust and resorted to a longer heat treatment $(19 \mathrm{~h})$, which may explain the different results. However, we followed the experimental setup of Wunderlich et al. (2014) very closely (ratios of substances in the cement, heating time, temperature) so that there is no straightforward explanation for the difference in their results. Besides the limited supply of moisture and hence a limitation in providing enough $\mathrm{HCl}$ or $\mathrm{Cl}_{2}$ for oxidation (see above), it is possible that the different yields are related to the use of different fired clays. For example, the chemical composition of the fired clay could be different (not specified in Wunderlich et al. 2014). Furthermore, the coarse-grained structure of the cement we used (0.1-4 $\mathrm{mm}$ ) compared to the fine-grained material used by Wunderlich et al. $(0-0.5 \mathrm{~mm})$ might have had a strong influence on the effectiveness of the cementation process. The larger spaces between the large grains of the fired clay could have prevented a closer contact of the cement and active ingredients with the gold surface in some areas and thus a more effective reaction. Finally, an influence of the thickness of the gold foils must be considered: While ours were about $\pm 300 \mu \mathrm{m}$, the gold foils of Wunderlich et al. (2014) were adjusted to $250 \mu \mathrm{m}$.

Regarding $\mathrm{Sb}, \mathrm{Bi}, \mathrm{Sn}$ and $\mathrm{Ni}$, the experiments $\mathrm{CM} 2$ were also more efficient, as DF values of less than 0.05 ( $\mathrm{Sb}$ and $\mathrm{Bi}$ ) and of 0.1 to 0.3 ( $\mathrm{Sn}$ and $\mathrm{Ni}$ ) suggest a significantly stronger depletion than for the experiments CM1, where DFs were consistently above 0.1 (Figs. 6, 7; Table 4). The systematic difference is presumably due to the presence of sulphur species in the cementation mixture of $\mathrm{CM} 2$, which formed during the decomposition of the alum. All four elements have chalcophile affinities, thus they readily form sulphur compounds which might be mobilised as melts or volatile phases together with chlorides.
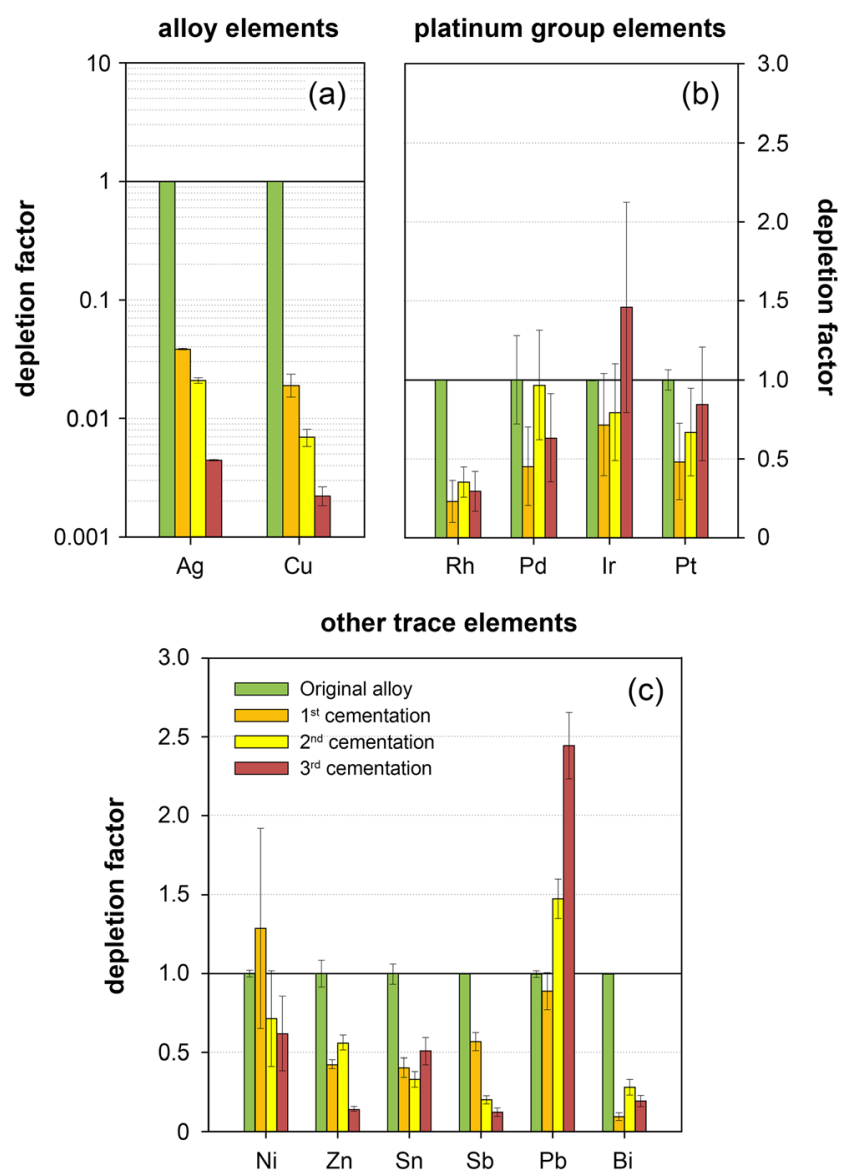

Fig. 6 Depletion of alloy (a), platinum group (b) and other trace elements (c) during the three cementation steps of CM1 test series. A depletion factor of 1 indicates that no depletion or enrichment (contamination) occurred and that the element $\mathrm{X} / \mathrm{Au}$ ratio was stable during all steps. A depletion factor $<1$ indicates depletion relative to $\mathrm{Au}$, while a factor $>1$ indicates relative enrichment (diagrams and data: N. Lockhoff)

Zinc becomes depleted in both experiments to similar degrees ( $\mathrm{DF} \sim 0.16$ ); however, an unexpected $\mathrm{Zn}$ enrichment from step 1 to 2 is observed before the strongest depletion occurs in the last step. We have no verifiable explanation for this observation, but we assume that volatile $\mathrm{Zn}$ phases precipitated on the gold surface after step 1 which were then incorporated in the gold during the re-melting in advance of the second cementation step.

With regard to the PGE (Ru, Pd, Pt, Ir), our study supports that of Blet-Lemarquand et al. (2017) indicating that they resist the $\mathrm{HCl}$ and $\mathrm{Cl}_{2}$ attack better than the other elements. $\mathrm{Rh}$ and Ir became depleted but have DF which are either constant within error or the elements show irregular depletion patterns with enrichment in step 2 or even step 3 (Figs. 6, 7; Table 4). Possibly, this is due to inhomogeneities in the samples, which is reflected in the relatively high standard deviation of the analyses. PGEs, especially $\mathrm{Ru}, \mathrm{Rh}$ and $\mathrm{Ir}$, are often not very homogeneously distributed in gold alloys. They are poorly soluble in gold and occur mainly in heterogeneous 


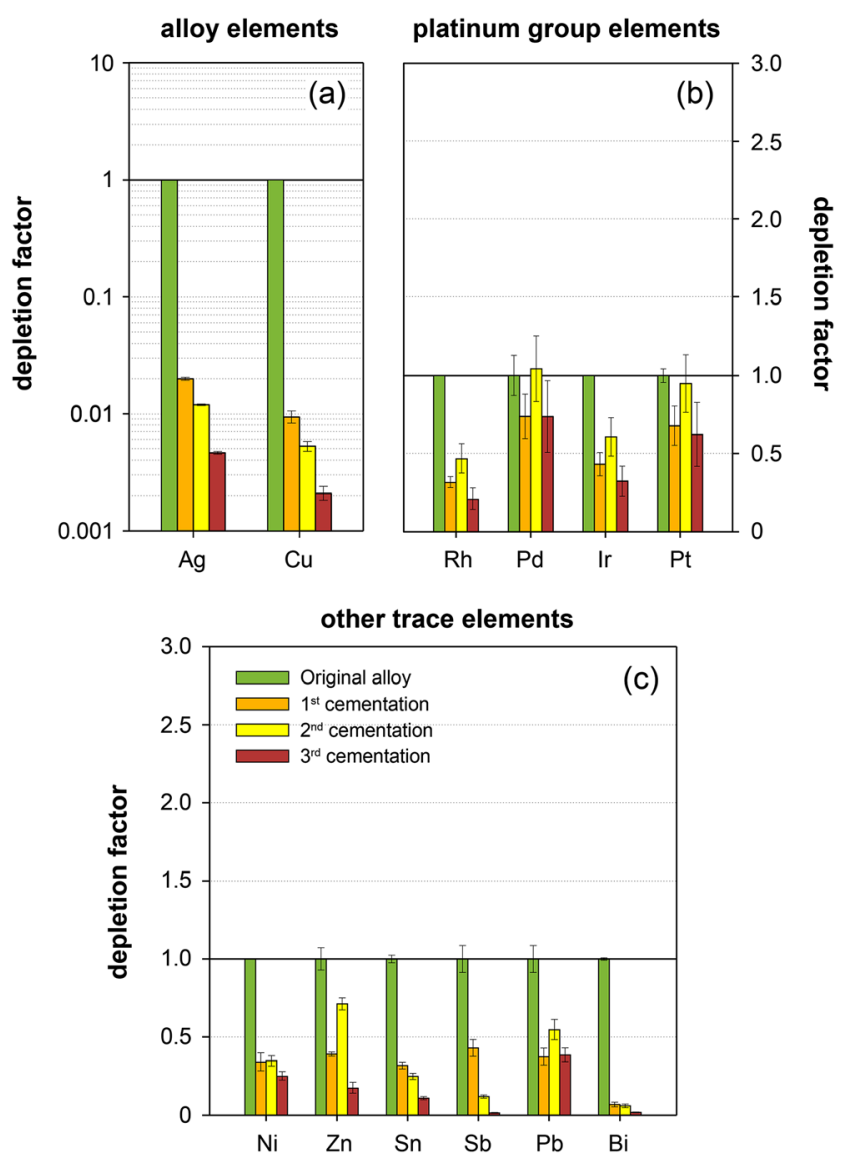

Fig. 7 Same as Fig. 6 but for CM2 test series (diagrams and data: N. Lockhoff)

(micro-)inclusions of different PGE minerals with high melting points compared to gold alloys. When gold alloys are (re)melted, such inclusions seem to segregate (Ogden 1976). For this reason, PGE inclusions appear to accumulate in certain areas of a gold object, instead of being homogenously distributed.

$\mathrm{Pt}$ and $\mathrm{Pd}$, for their part, tend to be more soluble in gold, even though submicroscopic inhomogeneities of them can occur in gold alloys (Ogden 1976, 1977). During the different cementation steps, both behave more stable than $\mathrm{Rh}$ and Ir. The $\mathrm{DF}_{\mathrm{Pd}}$ values range from 0.45 to 1.04 and $\mathrm{DF}_{\mathrm{Pt}}$ from 0.48 to 0.95 (Figs. 6, 7; Table 4), and despite the high analytical uncertainty, depletion in some steps is apparent. Experiments with gold alloys containing higher amounts of $\mathrm{Pt}$ and $\mathrm{Pd}$ would provide more accurate data and clarify the trends. Refining experiments carried out by Blet-Lemarquand et al. (2017) indicate that these two elements are reliable tracers of different refining processes (cupellation and cementation). However, their results are not directly comparable to ours, because the experiments were less efficient in the removal of $\mathrm{Ag}$ (and $\mathrm{Cu}$ ), which might have influenced the behaviour of the trace elements, including Pt and Pd.
It should also be emphasised that the interpretation of trace element concentrations in relation to whether the gold has been purified or not can be very difficult in individual cases. In particular, low concentrations and thus low analytical precision and contamination effects will constrain the validity of general guidelines and may limit their applicability. In practice, only the Ag content might remain a reliable indicator for the cementation process. However, the range of Ag concentrations in natural gold is wide and therefore in gold objects with $<3.5 \% \mathrm{Ag}$, it will not be a clear fingerprint of a deliberate purification process. In special cases, other elements, for example $\mathrm{Cu}$, could also indicate the purification process, but it must be taken into account that they can be altered by various goldsmithing processes.

\section{Fractionation of stable $\mathbf{A g}$ and $\mathrm{Cu}$ isotopes during experimental cementation}

The course of isotope fractionation observed from our samples and those of the experiments of Wunderlich et al. (2014) follows the same exponential trend despite the different chemical composition of the starting alloys. Up to a loss of about $92 \%$ compared to the original alloy, isotope fractionation of $\mathrm{Ag}$ is rather small $\left(\Delta^{109} \mathrm{Ag}<+1 \%\right.$ ) , but rises exponentially when further Ag is removed (Fig. 3a). At a loss in Ag of $99 \%$, the fractionation reaches more than $+7.6 \%$ in $\Delta^{109} \mathrm{Ag}$. The same applies to the $\mathrm{Cu}$ isotope ratios, which display fractionation values of $\Delta{ }^{65} \mathrm{Cu}$ around $+11 \%$ at the end of the cementation treatment (Fig. 3b). The cementation process thus induces a strong relative enrichment of the heavy isotopes and more so for $\mathrm{Cu}$ than for $\mathrm{Ag}$. The smaller mass-dependent fractionation of $\mathrm{Ag}(Z=47)$ versus $\mathrm{Cu}(Z=29)$ under similar conditions (temperature, bonding environment, redox conditions) is expected because mass-dependent isotope fractionation decreases with increasing atomic number $Z$ (Hoefs 2018). The isotope variation in nature is also significantly larger for $\mathrm{Cu},>$ $+10 \%$ (e.g. Mathur et al. 2010; Moynier et al. 2017), than that of Ag, $\sim 3 \%$ (e.g. Argapadmi et al. 2018; Mathur et al. 2018; Voisey et al. 2019).

We consider the following mechanisms to dominate both fractionation and separation steps:

- Oxidation of $\mathrm{Ag}$ and $\mathrm{Cu}$ metal in the gold alloy

- Separation of chloride and possibly sulphur compounds of $\mathrm{Ag}$ and $\mathrm{Cu}$ from the gold alloy by diffusion (solid, melt, vapour)

- Diffusion of $\mathrm{Ag}$ and $\mathrm{Cu}$ through the gold lattice

The processes that could operate during these two scenarios include equilibrium and kinetic fractionation (evaporation, diffusion), changes in redox and salinity, and mixing (contamination) of isotopic reservoirs. Significant effects due to temperature changes are unlikely as all steps of the 
experiments were performed at equal temperatures and the cementation process is only effective at high temperatures $\left(>600^{\circ} \mathrm{C}\right)$. Therefore, no significant isotope fractionation should occur at lower temperatures during the heating interval.

Overall, the whole cementation process involving steps 1 to 3 might be described as a single kinetic experiment, because the variation of the isotopic compositions follows an exponential law (Fig. 8). It reflects a kinetic fractionation where the product (Ag- and $\mathrm{Cu}$-rich cement) is removed from the depleted gold reservoir during each step. Each single step as a whole might be better described as an equilibrium system, as each step takes place in a closed system (covered crucible) at high temperature. Each step involves the same reactants and products and implies similar chemical-physical reactions including redox processes, melting, evaporation and diffusion, thus equilibrium and kinetic isotope fractionation processes.

At each step, the transition of $\mathrm{Cu}^{0}$ and $\mathrm{Ag}^{0}$ in the gold to $\mathrm{Cu}^{+}, \mathrm{Cu}^{2+}$ and $\mathrm{Ag}^{+}$complexes are redox reactions involving the oxidation of the metal $\left(\mathrm{Ag} \leftrightarrow \mathrm{Ag}^{+}+\mathrm{e}^{-}, \mathrm{Cu} \leftrightarrow \mathrm{Cu}^{+}+\mathrm{e}^{-}\right.$, $\mathrm{Cu} \leftrightarrow\left(\mathrm{Cu}^{++}+2 \mathrm{e}^{-}\right)$. Several studies of $\mathrm{Ag}$ and other transitional metals $(\mathrm{Cu}, \mathrm{Ni}, \mathrm{Zn}, \mathrm{Fe}, \mathrm{Cd})$ have shown that oxidation and the associated charge transfer at low temperatures lead to a relative enrichment of heavy isotopes in the oxidised species (e.g. Asael et al. 2012; Kavner et al. 2008; Black et al. 2011; Wiederhold 2015 and references therein; Mathur et al. 2018), while the remaining and more reduced fraction is enriched in the lighter isotopes. For a leaching experiment of native silver, Mathur et al. (2018) reported a greater $\delta^{109} \mathrm{Ag}$ value of the leach solution than of the starting material. The heavier isotope ${ }^{109} \mathrm{Ag}$ was preferentially released into solution during oxidation of native silver. Similarly, Argapadmi et al. (2018) suggested that hydrothermal $\mathrm{Ag}^{+}$(aq) complexes are enriched in ${ }^{109} \mathrm{Ag}$ relative to $\mathrm{Ag}^{0}$ (metal) in a solid solution with gold.

However, the isotope values determined by us point to the opposite direction (metal $=$ heavy; salt $=$ light) suggesting that a redox-driven isotope fractionation cannot explain the isotope fractionation in our experiments. Moreover, the extent of isotope fractionation observed in the low temperature studies is smaller than that observed here. Studies of the isotope fractionation in high-temperature systems of $\mathrm{Cu}$ and $\mathrm{Ag}$ are lacking, but it is generally expected that at high temperatures, the extent of isotope fractionation is much smaller. At high temperature, the nature of the binding may be different as its ionic character weakens and covalent components become stronger. It is even possible that the direction of isotope fractionation is reversed. Nevertheless, even if the principles deduced for redox reactions of the low-temperature studies $(<$ $400{ }^{\circ} \mathrm{C}$ ) do not apply to our high-temperature reactions between solid metals and salt melts, it is reasonable to assume that the isotope fractionation caused by redox reactions are too small to explain the whole isotope fractionation observed during each step in our experiments.

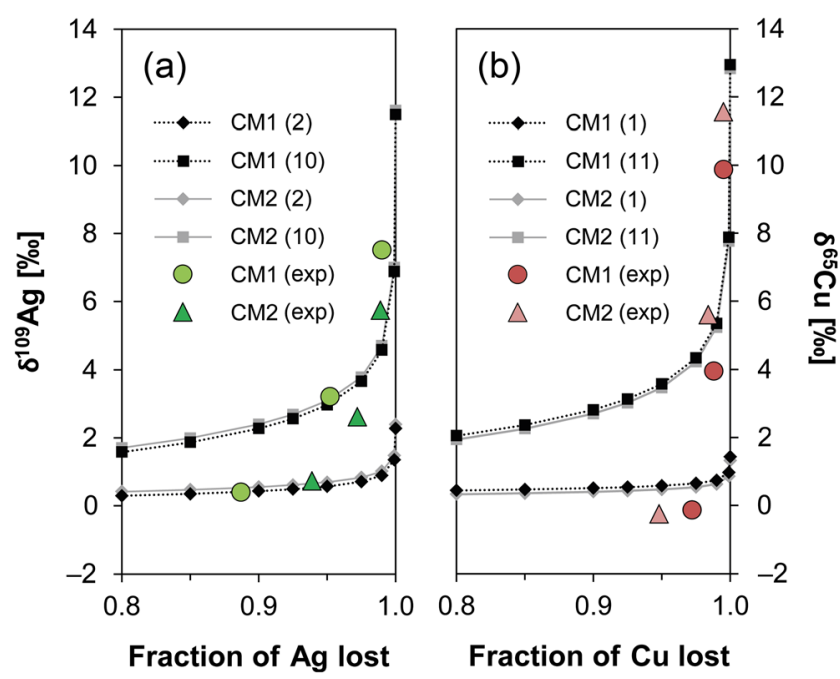

Fig. 8 Experimental $\mathrm{Ag}(\mathbf{a})$ and $\mathrm{Cu}(\mathbf{b})$ isotopic data (coloured symbols) and model calculations (black and grey symbols and lines) of the fractionation behaviour assuming fractionation factors of 2 and 10 for $\mathrm{Ag}$ and of 1 and 11 for $\mathrm{Cu}$ (fractionation are specified in brackets). Calculations were carried out according to Eqs. (17) and (18) (diagram and data: G. Brügmann; calculations based on Argapadmi et al. 2018)

Large isotope fractionation and high-temperature conditions rather suggest the interaction of kinetic processes. A large kinetic isotope effect should be expected during the infiltration of $\mathrm{Cl}_{2}, \mathrm{HCl}$ and $\mathrm{O}_{2}\left(\right.$ or $\mathrm{FeCl}_{3}$ ) along grain boundaries and cleavage surfaces into the solid gold alloy and the contemporaneous reaction with $\mathrm{Ag}$ and $\mathrm{Cu}$ to form chlorides and other, possibly sulphur-bearing compounds in experiment CM2. The effect is probably enhanced by the separation of the liquid phases out of the gold. Moreover, the transport of $\mathrm{Ag}$ and $\mathrm{Cu}$ atoms through the gold crystals should also give rise to large isotope separation. All processes are governed by diffusion, in which $\mathrm{Ag}$ and $\mathrm{Cu}$ compounds or atoms move along chemical gradients through the gold alloy and the gold lattice. The diffusion rates of the lighter isotopes $\left({ }^{63} \mathrm{Cu},{ }^{107} \mathrm{Ag}\right)$ are larger than those of the heavier ones $\left({ }^{65} \mathrm{Cu},{ }^{109} \mathrm{Ag}\right.$; Hoefs 2018,18 ). Discrimination of isotopes due to diffusion (chemical diffusion, Soret diffusion) is an effective and important process as shown by many geochemical studies (Hoefs 2018, 18; see Richter et al. 2009 and references therein). Thus, we propose that solid-state diffusion and the persistent and preferential removal of the light $\mathrm{Ag}$ and $\mathrm{Cu}$ isotopes by the removal of reaction products from the metal surface is the most important process causing the increase of the isotopic values in the gold reservoir. In addition, many of the metal salts have low melting points $\left(<800^{\circ} \mathrm{C}\right)$ or even high vapour pressures as indicated by the occurrence of $\mathrm{Ag}$ and $\mathrm{Cu}$ sublimates at the lid of the crucibles. This implies that the diffusion process is accompanied by Rayleigh distillation processes enhancing the extent of isotope discrimination.

During the first cementation step, however, $\mathrm{Cu}$ appears to behave differently, because the $\mathrm{Cu}$ isotopic composition of the 
residual gold was lighter than that of the starting alloy (Fig. $3 b)$. Maybe the rather complex redox processes involving $\mathrm{Cu}^{+}$ and $\mathrm{Cu}^{2+}$ dominated the evolution of the isotopic signatures in the first step (redox-driven fractionation). The extent of fractionation $\left(\Delta^{65} \mathrm{Cu}=-0.30\right.$ to $-0.53 \%$ o $)$ is at least well within that of two differently oxidised phases observed in lowtemperature redox experiments with $\mathrm{Cu}$ containing solutions (e.g. Ehrlich et al. 2004; Asael et al. 2012). Moreover, the variation and magnitude observed in weathered copper ores where multiple copper phases coexist are similar (e.g. Markl et al. 2006). Only when a sufficiently high amount of $\mathrm{Cu}$ was removed from the alloy in the following cementation steps (> $95 \%$ ), other effects such as diffusion and fractional precipitation dominated and reversed the fractionation. This could in fact explain the observed isotopic compositions in our sample set. The $\mathrm{Cu}$ isotopic composition of the cement for its part could have been altered by the presumed evaporation of $\mathrm{CuCl}_{2}$ or other processes. However, appreciating that the effect of high-temperature processes on the isotope fractionation is not known, more research is needed in order to explain this phenomenon.

The exponential evolution of the isotopic composition in the cemented gold is apparent from Figs. 3 and 8 and resembles that of fractional distillation or fractional precipitation (Rayleigh fractionation). Such fractionation models have been proposed for geological processes like the precipitation of $\mathrm{Ag}$ with native gold from hydrothermal solutions (Argapadmi et al. 2018; Voisey et al. 2019). In principle, however, such processes are the reverse of our experiment, i.e. the desilvering of gold with a 'hydrothermal' agent. Nevertheless, using Argapadmi et al.'s (2018) approach and adapting the specified fractionation factors, we are able to calculate the theoretical fractionation behaviour of $\mathrm{Ag}$ and $\mathrm{Cu}$ during the cementation process (Fig. 8) according to:

$\delta^{109} A g(1-f)=\delta^{109} A g_{\text {initial }}+\alpha_{A g} \times \operatorname{lnf}$

and

$\delta^{65} C u(1-f)=\delta^{65} C u_{\text {initial }}+\alpha_{C u} \times \operatorname{lnf}$

where $\delta^{109} A g_{\text {initial }}$ and $\delta^{65} \mathrm{Cu}_{\text {initial }}$ are the isotopic compositions of the starting gold alloy (in \%o), $\alpha_{A g}$ and $\alpha_{C u}$ the fractionation factors in $10^{3} \ln \alpha, f$ the fraction of the remaining $\mathrm{Ag}$ or $\mathrm{Cu}$ in gold and $\delta^{109} \mathrm{Ag}$ and $\delta^{65} \mathrm{Cu}$ the theoretical isotopic compositions at the fraction $1-f$ of the initial $\mathrm{Ag}$ or $\mathrm{Cu}$ lost from the gold.

Although the overall trends for both elements could be reproduced qualitatively by the model calculations, there are some important differences in detail: Based on the measurements of the $\mathrm{Ag}$ isotopic composition in gold from the first step and the cementation mixtures, fractionation factors of about 4 (CM1) to 7 (CM2) would have been expected (Tables 3 and 5) assuming these phases were in equilibrium.
For $\mathrm{Cu}$, these values would range from about 1 (CM1) to 3 (CM2). In order to explain the enrichment of heavy isotopes observed during the second and third step of the cementation, however, the fractionation factors have to be between 9 and 11 for $\mathrm{Cu}$ and 7 and 10 for $\mathrm{Ag}$ and thus significantly higher (Fig. 8 , lines with square symbols). With these values, it is possible to model the extent of isotope discrimination.

However, both models do not explain the isotopic compositions observed during step one of the cementation experiments, because $\mathrm{Cu}$ and $\mathrm{Ag}$ isotopic compositions follow a significantly lower trend defined by fractionation factors of less than 2 (Fig. 8, lines with diamond symbols). This implies that during step one, where most of the $\mathrm{Ag}$ and $\mathrm{Cu}$ were removed from the gold, the oxidising processes, the formation and separation of the salt components, differed significantly from the later stages. The processes leading to the removal of $\mathrm{Ag}$ and $\mathrm{Cu}$ are complex and a detailed explanation cannot be given at this time. However, at this stage, the effectiveness of the process is crucially dependent on the supply of $\mathrm{NaCl}$ and other reactants $\left(\mathrm{Cl}_{2}, \mathrm{HCl}, \mathrm{O}_{2}\right.$ and/or $\left.\mathrm{FeCl}_{3}\right)$ which will control the progress of the reaction along grain boundaries in the gold alloy. In addition, the removal of the salt products controls the effectiveness of the removal of $\mathrm{Cu}$ and $\mathrm{Ag}$ out of the grain. Possibly, there were not enough open pathways available due to the formation of a large amount of alt components. This would imply that Rayleigh fractionation was less effective during step one than during steps two and three and that the concentrations and isotope composition we measured at step one in the gold and cement fractions do not represent equilibrium conditions. This may be due to a too short heating interval or exhaustion of reactive agents and thus an incomplete depletion reaction after the $12 \mathrm{~h}$ in our case (compared to $18 \mathrm{~h}$ in the study of Celauro et al. 2017).

\section{Isotopic variations in gold artefacts and recognising refining processes}

The overall aim of our study was to develop a sensitive tool for the identification of cemented and de-silvered gold in general. Therefore, a combined evaluation of the experiments and artefacts is given in the following paragraphs. Figure 9 compiles the sparse literature data of $\mathrm{Ag}$ and $\mathrm{Cu}$ isotope ratios in native gold and the data from our measurements. Silver is a major component in lode gold and detrital gold nuggets (typically 5-20 \% Ag; Hough et al. 2009) as well as in archaeological gold artefacts (e.g., Hartmann 1970, 1982; Schlosser et al. 2012). The variation in $\delta^{109} \mathrm{Ag}$ in lode deposits and detrital gold nuggets ranges from -0.83 to $+0.74 \%$ o (Chugaev and Chernyshev 2012; Argapadmi et al. 2018; Baron et al. 2019; Brügmann et al. 2019; Voisey et al. 2019). In comparison, the $\mathrm{Ag}$ isotopic composition of the experimentally cemented gold after a Ag loss of $89 \%$ (CM1a) and $94 \%$ (CM2a) during the first cementation step 
varies between +0.41 and $+0.73 \%$ (Fig. 9). These values overlap with the heavier end of the natural range so it would not be possible to distinguish refined from natural gold using this isotope system alone. For example, if a cemented gold with $2 \% \mathrm{Ag}$ was derived from a gold alloy originally containing 15 to $20 \% \mathrm{Ag}$ (meaning an $\mathrm{Ag}$ loss of 87 to $90 \%$ ), the resulting $\delta^{109} \mathrm{Ag}$ value may well be within the natural isotopic variation of $\mathrm{Ag}$ in gold. However, the consideration of trace element concentrations such as $\mathrm{Bi}, \mathrm{Sb}, \mathrm{Sn}, \mathrm{Zn}$ and the $\mathrm{Cu}$ isotopic composition could eventually provide additional constraints to help distinguishing between natural and refined gold alloys.

If the cumulative removal of $\mathrm{Ag}$ increases to more than ca. $94 \%$, the Ag in the refined gold is extremely enriched in the heavy isotope resulting in an isotopic composition far beyond that of natural gold (Fig. 9). So, even if the analysed metal still contains about $2 \% \mathrm{Ag}$, but started from a gold alloy with originally $55 \% \mathrm{Ag}$ (as in our experiments), the fractionation can already be extreme. In this case, it is possible to recognise the refining process despite the elevated concentration of Ag. It is remarkable that the magnitude of fractionation appears to be independent of the original Ag concentration as implied by the data from our samples and that of Wunderlich et al. (2014) (Fig. 3a). The critical parameter is the extent of Ag loss from the original reservoir. It is also noteworthy that in detail the fractionation curve of the experiments with alum differs from that of the experiment with $\mathrm{NaCl}$ alone. However, this is quantitatively, and thus practically, significant only at an extreme depletion of $\mathrm{Ag}$ of more than $95 \%$ (Figs. 3a and 8).

Several of the examined gold artefacts (some coins and the finger ring) have very heavy $\mathrm{Ag}$ isotopic compositions $\left(\delta^{109} \mathrm{Ag}>+0.8 \%\right.$ ) that lie outside the natural variation

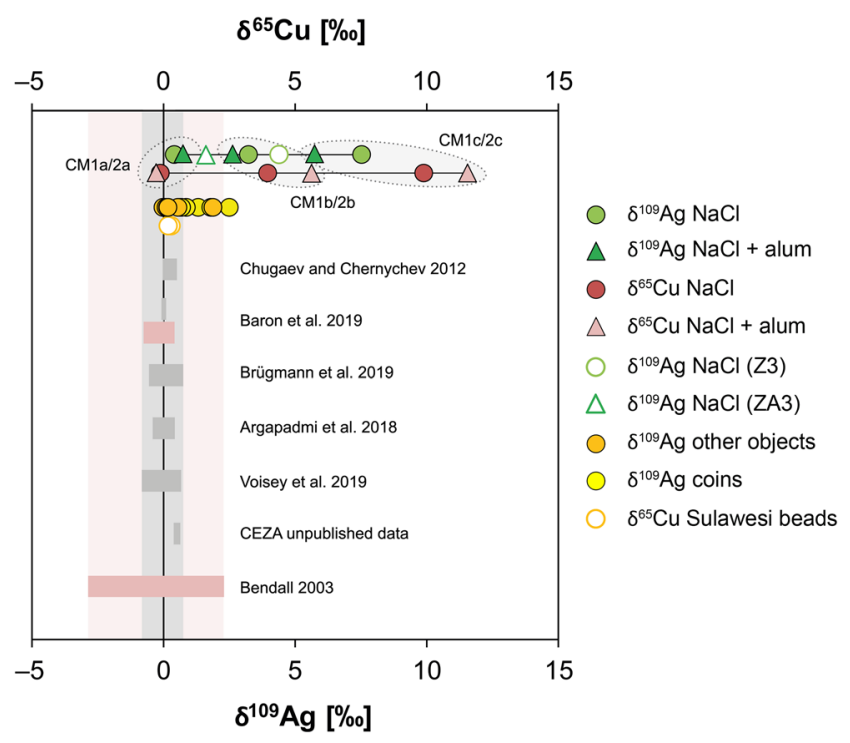

Fig. 9 Variation of $\mathrm{Ag}$ (grey bars) and $\mathrm{Cu}$ isotope ratios (rose bars) in lode and placer gold deposits compared to the results of this study (diagram: D. Berger, data: G. Brügmann, N. Lockhoff)
(Fig. 4a and 9; Table 6). Such artefacts have also very low Ag contents of less than $2.5 \%$. If neither cupellation nor any other pyrometallurgical process is capable of removing as much $\mathrm{Ag}$ from gold as cementation and also do not induce such extreme mass-dependent fractionation, then the Ag isotopic signature in these artefacts was definitely caused by gold parting. However, this general conclusion will need to be constantly reviewed in the future as the presently limited number of $\mathrm{Ag}$ isotopic data of natural gold alloys increases. There is also an urgent need to check the behaviour of $\mathrm{Ag}$ isotopes during the cupellation process.

The remaining gold objects have $\mathrm{Ag}$ isotope ratios ranging from about 0 up to $+0.68 \%$, values which overlap with the range observed in natural gold alloys (Fig. 4a; Table 6). This group includes one coin (MA-197853) with $3.6 \% \mathrm{Ag}$, and most of the artefacts recovered from archaeological contexts. The necklace and bracelet from Mühleberg-Allenlüften (MA-197619 and MA-197620), the Sulawesi beads (MA-195226 and MA-195233) as well as the Nebra Sky Disc (FG-030531) have high Ag contents between 11 and $55 \%$, suggesting that they were prepared from natural gold alloys. Their average Ag isotopic composition $\left(\delta^{109} \mathrm{Ag}=0.10 \pm 0.16 \%\right.$ (2SD) $)$ is within the variation of gold deposits. It is also similar to the bulk silicate Earth (BSE) of $0.22 \pm 0.07 \%$, which reveals that gold deposits are ultimately of crustal origin (Schönbächler et al. 2010). Interestingly, ancient and post-mediaeval silver coins display a similar $\mathrm{Ag}$ isotopic variation of between -0.2 to $+0.2 \%$ (Desaulty et al. 2011; Desaulty and Albarède 2013; Albarède et al. 2016; Milot et al. 2021) as the gold artefacts analysed by us. Although the conditions of silver cannot be transferred to gold, it can be speculated that a comparably narrow variability around 0 is also characteristic for objects made of un-refined gold (see Fig. 4a). Therefore, the comparison with silver objects can help interpretation as long as the number of comparative analyses of gold artefacts is limited.

For some of the investigated gold objects, which include the gold applique from Rülzheim (MA-192493) and some coins, the Ag contents and isotopic compositions do not give a clear indication of de-silvering of gold. They have Ag concentrations below $3 \%$, but their isotopic compositions range from +0.54 to $+0.85 \%$ and overlap therefore with the heavier part of the range reported from gold deposits (Fig. 9; Table 6). Either gold parting is masked by the natural variation in this case or the alloys actually represent native gold. Given the low contents of trace elements (Online Resource 3 ), the first explanation appears to be more likely. In addition, their isotopic compositions lie outside the range observed in silver artefacts (see Fig. 4a), which could be an indication of the cementation process. However, this would need to be confirmed by extensive isotopic analysis of other gold objects in order to better define their variation. 
Using the experimental results (Ag content and isotopic composition of the sample) and presuming a certain initial isotopic value for a gold object, it is in theory possible to estimate the efficiency of the cementation procedure and the original Ag content of the gold alloys, respectively the gold ores. Let us, for example, take the Ag isotopic composition of $\delta^{109} \mathrm{Ag}+2.49 \%$ of the cemented Tiberian aureus (MA197600) (cf. Table 6) and assume an $\delta^{109} \mathrm{Ag}=0$ of the original gold; this would imply a fractionation of $+2.49 \% \circ \Delta^{109} \mathrm{Ag}$ relative to the parent un-refined metal. Applying the data from the $\mathrm{NaCl}$ experiment (CM1), such an isotope fractionation corresponds to an Ag loss of about $94.7 \%$ (see Fig. 4b). Taken the model calculations in Fig. 8a, the loss would be about $94 \%$ using a fractionation factor of 10. The actual Ag concentration in the coin is $0.42 \%$; thus, the original gold alloy would have contained ca. $7.9 \% \mathrm{Ag}$ using the equation

$A g_{\text {initial }}=\frac{A g_{\text {actual }} \times 100}{\left(100-\operatorname{loss}_{A g}\right)}=\frac{0.42 \times 100}{(100-94.7)}[\%]$.

Considering the range of isotopic compositions of native gold deposits $(-0.83$ to $+0.74 \%$ ) and the resulting theoretical Ag loss by dropping a perpendicular on the abscissa in Fig. 4b, calculation of the Ag concentration following Eq. (19) of the un-cemented gold gives the theoretical range from 6.9 to $9.1 \%$.

The finger ring from Bad Dürrnberg (MA-200664) also consists of a cemented gold alloy as indicated by its heavy $\mathrm{Ag}$ isotopic composition of $+1.87 \%$ and rather low $\mathrm{Ag}$ content of $2.5 \%$. Applying the same approach as above yields an $\mathrm{Ag}$ concentration of between 36.3 and $48.9 \%$ in the original gold alloy. Such a high Ag content is not very common in prehistoric gold artefacts (normally between ca. 10 and $25 \%$ Ag) but was at least found in several, albeit un-cemented gold objects from the Dürnberg (Hartmann 1978). On the other hand, Stöllner (2018) identified prills of potentially desilvered gold $(1.0 \pm 1.8 \% \mathrm{Ag})$ in a ceramic mould from the same site, and there is another Ag-poor gold finger ring from the settlement (unpublished data N. Lockhoff, CEZA). The calculated value for the original gold of the present finger ring as well as the proof of cemented gold thus has archaeological counterparts, which underlines the relevance of the approach used. This is the reason why we have applied them to the other gold artefacts of the study with very heavy isotopic compositions, whose estimated Ag contents are listed in Table 6.

Of course, the procedure described is only a very rough estimate. If the ancient cementation processes used recipes that differed significantly from ours, the fractionation behaviour would (marginally) change and new fractionation factors would have to be adapted. Moreover, the approach would be compromised if the recycling of gold objects had been widespread, resulting in the mixing of gold batches. This could have been the case with some coins examined in this study. It is well established that metals used for minting were re- cycled, re-used and mixed (e.g. Gondonneau et al. 2002; Vîlcu et al. 2010; Schlosser et al. 2012; Blet-Lemarquand et al. 2015), often with the aim to intentionally debase the original metal. The Ag content and the isotopic composition of the Augustan aureus MA-197599 (0.12\% Ag; $\delta^{109} \mathrm{Ag}=$ $+1.79 \%$ ) , for instance, clearly suggests that it consists of cemented gold, but the estimated Ag concentration of the original gold is only 1.6-2.3\% (Fig. 4c; Table 6). Natural gold alloys with such compositions do exist and, in this case, the estimated concentration would indeed represent that of the natural gold alloy. However, since Ag-poor gold deposits are rare, it is also reasonable to assume that this composition represents the average of a collection, i.e. a mixture, of cemented with low- or unpurified gold. In this sense, the gold of the coin could in fact have been deliberately debased. The same conclusion could apply to the Tiberian aureus (MA-197600) which has a low Ag content $(0.42 \%)$ and a high Ag isotopic composition $\left(\delta^{109} \mathrm{Ag}=+2.49 \%\right.$ ) . It is also possible that coins with $\mathrm{Ag}$ contents of less than $2.3 \% \mathrm{Ag}$ and with 0.62 to $0.86 \% \delta^{109} \mathrm{Ag}$ such as the aureus of Nero (MA-197601; Table 6) represent blends of cemented with natural Ag-rich gold. Therefore, the estimated initial concentration of $10.8 \%$ Ag does not reflect the composition of the natural gold but of the mixture.

The situation is more complex with $\mathrm{Cu}$ isotopes in gold. Very little is known about the isotopic composition of $\mathrm{Cu}$ either in gold deposits or archaeological gold artefacts. Only two studies reported on $\delta^{65} \mathrm{Cu}$ data of gold ores ranging from -2.87 to $+2.29 \%$ (Bendall 2003; Baron et al. 2019). This variation is rather small compared with data from $\mathrm{Cu}$ ores and minerals (ca. -17 to $+10 \%$; e.g. Mathur et al. 2010; Moynier et al. 2017). At present, our study cannot evaluate the implications of $\mathrm{Cu}$ isotope fractionation observed in the cementation experiments for archaeological gold objects. Except for the two Sulawesi beads, we have not determined the $\mathrm{Cu}$ isotopic composition in the gold from this study. This is due to the generally low $\mathrm{Cu}$ concentrations in the objects $(<0.5 \%)$ and the small sample sizes (few mg), which did not allow a precise determination with the available analytical setup. Accordingly, it is not possible to fit our samples in the small corpus of available $\mathrm{Cu}$ isotope data from archaeological objects in the literature (Bendall 2003, Jansen 2019).

However, some general implications can be discussed, showing that interpretations of $\mathrm{Cu}$ isotope data need to be carefully evaluated in terms of the identification of the refining process and conclusions about the efficiency of the processes involved and the original gold composition. Our experiments show that the $\mathrm{Cu}$ content is effectively reduced by the cementation technique, which is accompanied by a large fractionation of the $\mathrm{Cu}$ isotope ratios. The simultaneous depletion of $\mathrm{Ag}$ and $\mathrm{Cu}$ together with isotopic discrimination leading to the relative enrichment of the heavy isotopes would be a clear fingerprint of the cementation process. 
However, there are several ways to modify the $\mathrm{Cu}$ concentration and thus its isotopic signature in the gold either during or after the refining procedure. Contamination with copper can also occur before refining, for example when alluvial gold-containing copper minerals are melted. The same could happen when a crucible was used which contained residues of copper or bronze from a previous melting event. Since contamination in this case occurred before gold refining, Ag and $\mathrm{Cu}$ isotopes should fractionate simultaneously even if the $\mathrm{Cu}$ signature of the original gold was altered. This kind of contamination, however, is difficult to detect, and therefore, conclusions about the original composition of the gold can be misleading.

Another source is mentioned by Theophilus Presbyter (Hawthorne and Smith 1979, 108-109; Brepohl 1987, 107109), who wrote that $\mathrm{Cu}$ was added to the gold during cementation in mediaeval times. This would alter the $\mathrm{Cu}$ isotopic signal induced by the parting process as later alloying with $\mathrm{Cu}$ would do. For example, cemented gold objects may have been deliberately alloyed with $\mathrm{Cu}$ (up to few percent) to harden the gold without changing its colour but to make it more resistant to mechanical stress. Depending on the mass ratio of original to added $\mathrm{Cu}$, the $\mathrm{Cu}$ isotopic signature can be lowered significantly so that the refining information is blurred or even completely hidden. The same result applies when cemented, and thus, gold with highly fractionated $\mathrm{Cu}$ is re-cycled and eventually mixed with un-cemented gold.

Finally, the $\mathrm{Cu}$ isotopic composition could be changed by other refining techniques. As mentioned in the second chapter, gold can also be refined by cupellation. This removes many trace elements and reduces also the $\mathrm{Cu}$ concentration in the gold without affecting $\mathrm{Ag}$. Removing the $\mathrm{Cu}$ by co-melting gold with $\mathrm{Pb}$ followed by cupellation could possibly also have some influence on the $\mathrm{Cu}$ isotopes, even though the effect should not be as pronounced as with the cementation. There should be no substantial diffusion and evaporation of copper or copper compounds. Thus, overall, the cupellation process could cause a small, perhaps even a non-negligible, change in the isotopic composition. However, the direction of possible fractionation is not predictable and the extent of fractionation needs further investigation. It should also be a subject of further research on how copper isotopes in gold alloys behave under corrosive attack. Jansen $(2019,106-109)$ reports on inhomogeneities of copper isotope ratios in gold artefacts from ancient Ur and raises fractionation upon corrosion as a possible explanation.

\section{Conclusions}

The present study demonstrates that the ancient gold parting process by salt cementation can be identified in gold artefacts by measuring the $\mathrm{Ag}$ isotopic composition. During purification, the processed gold is extremely depleted in the light silver isotope ${ }^{107} \mathrm{Ag}$ most probably due to vaporisation of reaction products and isotope effects during diffusion in the gold. This leads to a change of $\mathrm{Ag}$ isotope ratios in the gold towards heavier compositions, which can be distinguished from native gold when ca. $93-94 \%$ of the original Ag has been removed. If this condition is met, the Ag isotopic composition falls outside the natural range. $\mathrm{Cu}$ isotopes discriminate in a similar way between the metallic phase and the $\mathrm{Cu}$ salt in the cement, leading to even more extreme and heavy isotopic compositions in the gold. Even though $\mathrm{Cu}$ isotope ratios could thus be an additional indicator for cementation, their practical value as proof for the application of this technique could indeed be limited for various reasons. Nevertheless, $\mathrm{Cu}$ isotope ratios could still be a valuable instrument in the identification of gold batches or mixing and recycling of un-refined and/or non-refined gold, especially when they are combined with $\mathrm{Ag}$ isotope ratios and trace element concentrations. Mixing lines and clustering will provide information on the relationships among artefacts and help reconstruct process chains and trade networks.

The Ag isotope ratios for their part provide a powerful tool for detecting gold parting by the salt process. This approach could be applied to gold coins or historical artefacts and also for prehistoric gold objects. In this respect, it is important to highlight the parted gold of the finger ring from the Dürnberg. It dates to the La Tène B period, ca. 320 to $250 \mathrm{BC}$, and originates from a region that was not known for extensive gold parting at this time. In addition, the object is not directly related to monetary purposes. The present result is thus the first tangible evidence for the processing of refined gold north of the Alps and maybe also for the application of this technology by the Celts, though it is traditionally regarded as being related to economic or monetary contexts (Ramage and Craddock 2000). The finding is even more important against the background of the casting mould from the Dürnberg with traces of apparently pure gold (Stöllner 2018). Although both objects (and another one) do not necessarily mean that parting was carried out at this site, the nearby Iron Age salt mine with its sources of rock salt as well as the strategic location of the settlement could have been crucial factors for establishing an infrastructure for gold refining. The well-known gold sources in the Salzach River, the Tauern Mountains and other nearby locations would be further important criteria. It is, however, also possible that purified gold coins from the Mediterranean and elsewhere were reworked into jewellery at the Dürnberg. These diametrically opposed interpretations illustrate the need for more isotopic analyses of gold objects, not least because it still appears possible that cementation of gold was practiced much earlier with the aim of changing the colour of the gold or its mechanical properties such as ductility. We 
cannot prove the latter at present, but if gold cementation was practiced before the time of Sardis, it would be preserved in the gold's isotopic signature.

Our results have other important implications for the investigation of gold objects with $\mathrm{Ag}$ and $\mathrm{Cu}$ isotopes. Baron et al. (2019) recently stated that $\mathrm{Ag}$ and $\mathrm{Cu}$ isotopes may have great potential in gold provenancing, but this statement has to be qualified in the light of our results. Fractionation due to cementation drastically changes the isotopic composition of $\mathrm{Ag}$ and $\mathrm{Cu}$, making classical provenance studies on refined gold impossible. This is particularly true for gold with very low contents of both $\mathrm{Ag}$ and $\mathrm{Cu}$, i.e. below ca. $1 \%$ for $\mathrm{Ag}$ and $0.1 \%$ for $\mathrm{Cu}$. However, since we are not aware of the original gold composition of artefacts, also objects with $\mathrm{Ag}$ concentrations below $3 \%$ should be treated with caution. Even a loss of $\mathrm{Ag}$ and $\mathrm{Cu}$ of only $90 \%$ can modify the isotopic signatures in such a way that they differ significantly from the parent gold source. Interpreting the $\mathrm{Ag}$ and $\mathrm{Cu}$ isotope ratios of gold objects is thus not a straightforward issue per se. In the future, we will analyse gold ores and more gold objects from historical and prehistoric times to obtain an even better understanding of the cultural-historic background and to eventually find evidence for earlier refining procedures.

Supplementary Information The online version contains supplementary material available at https://doi.org/10.1007/s12520-021-01369-2.

Acknowledgements We are grateful to the help of the Generaldirektion Kulturelles Erbe (GDKE), Speyer (Ulrich Himmelmann), Germany, the Landesmuseum für Vorgeschichte Halle (Harald Meller), Germany and the Keltenmuseum Hallein (Holger Wendling), Austria, for permitting us to sample and analyse the archaeological objects. We are also indebted to the generous help of the Reiss-Engelhorn-Museen, Mannheim (Claudia Braun), Germany, and a private collector who provided us with the gold coins for the study. Barbara Armbruster (University of Toulouse) and Ulrich Himmelmann (GDKE Speyer) are kindly acknowledged for supplying qualitative photos of the archaeological objects from Dürrnberg, Mühleberg-Allenlüften and Rülzheim. We also thank the two reviewers who contributed significantly to improving the originally submitted manuscript.

Author contributions Conceptualisation: Daniel Berger, Michael Brauns; Methodology: Daniel Berger, Michael Brauns, Gerhard Brügmann, Nicole Lockhoff; Formal analysis and investigation: Daniel Berger, Gerhard Brügmann, Nicole Lockhoff; Writing - original draft preparation: Daniel Berger; Writing - review and editing: Daniel Berger, Michael Brauns, Gerhard Brügmann, Nicole Lockhoff, Ernst Pernicka; Supervision: Daniel Berger, Michael Brauns

Funding Open Access funding enabled and organized by Projekt DEAL.

Availability of data and material All data used for the study is included in this paper or in the Supplementary Material. All materials are stored at CEZA, Mannheim, Germany.

\section{Declarations}

Ethics approval Not applicable.
Consent to participate Not applicable.

Consent for publication Not applicable.

Competing interests The authors declare no competing interests.

Open Access This article is licensed under a Creative Commons Attribution 4.0 International License, which permits use, sharing, adaptation, distribution and reproduction in any medium or format, as long as you give appropriate credit to the original author(s) and the source, provide a link to the Creative Commons licence, and indicate if changes were made. The images or other third party material in this article are included in the article's Creative Commons licence, unless indicated otherwise in a credit line to the material. If material is not included in the article's Creative Commons licence and your intended use is not permitted by statutory regulation or exceeds the permitted use, you will need to obtain permission directly from the copyright holder. To view a copy of this licence, visit http://creativecommons.org/licenses/by/4.0/.

\section{References}

Albarède F, Blichert-Toft J, Rivoal M, Télouk P (2016) A glimpse into the Roman finances of the Second Punic War through silver isotopes. Geochem Perspective Lett 2:127-137

Albarède F, Blichert-Toft $\mathrm{J}$, de Callataÿ F, Davis G, Debernardi P, Gentelli L, Gitler H, Kemmers F, Klein S, Malod-Dognin C, Milot J, Télouk P, Vaxevanopoulos M, Westner K (2020) From commodity to money: the rise of silver coinage around the ancient Mediterranean $\left(6^{\text {th }}-1^{\text {st }}\right.$ century BCE). Archaeometry 62(6):2020

Argapadmi W, Toth ER, Fehr MA, Schönbächler M, Heinrich CA (2018) Silver isotopes as a source and transport tracer for gold: a reconnaissance study at the Sheba and New Consort gold mines in the Barberton Greenstone Belt, Kaapvaal Craton, South Africa. Econ Geol 113(7):1553-1570

Asael D, Matthews A, Bar-Matthews M, Harlavan Y, Segal I (2012) Tracking redox controls and sources of sedimentary mineralization using copper and lead isotopes. Chem Geol 310-311:23-35

Baron S, Tamas CG, Rivoal M, Cauuet B, Télouk P, Albarède F (2019) Geochemistry of gold ores mined during Celtic times from the North-Western French Massif Central. Sci Rep 9:17816

Baxter DC, Rodushkin I, Engstrom E, Malinovsky D (2006) Revised exponential model for mass bias correction using an internal standard for isotope abundance ratio measurements by multi-collector inductively coupled plasma mass spectrometry. J Anal At Spectrom 21(4):427-430

Bayley J (1991) Archaeological evidence for parting, in Archaeometry '90 (eds. E. Pernicka and G. A. Wagner), 19-28, Birkhäuser, Basel

Bayley J (1992) Anglo-Scandinavian non-ferrous metalworking from 16-22 Coppergate, The Archaeology of York 17, The small finds 7, 737-850, Council for British Archaeology, London

Bayley J, Budd P, Foley K, Heyworth M, Laidlaw M, Webb J, White R, Wilthew P (2008) Lincoln: Evidence for metalworking on Flaxengate and other sites in the city. Technology report, Research Department Report Series 67-2008, English Heritage, Portsmouth

Bendall, C (2003) The application of trace element and isotopic analyses to the study of Celtic gold coins and their metal sources, Ph.D. thesis Frankfurt University

Berger D (2016) Zur Technologie frühbronzezeitlicher Tauschierarbeiten nördlich der Alpen mit besonderer Berücksichtigung des Schwertes aus den "Marais de Nantes", in Verborgenes Wissen. Innovation und Transformation feinschmiedetechnischer Entwicklungen im diachronen Vergleich (eds. B. Armbruster, H. Eilbracht, O. Hahn 
and O. Heinrich-Tamaska, O.), 87-116, Berlin Studies of the Ancient World 35, Edition Topoi, Berlin

Black JR, Crawford JA, John S, Kavner A (2011) Redox driven stable isotope fractionation, in Aquatic redox chemistry (eds. P. G. Tratnyek, T. J. Grundl and S. B. Haderlein), 345-360, ACS Symposium Series 1071, Oxford

Blet-Lemarquand M, Nieto-Pelletier S (2020) Depth profile LA-ICP-MS analysis of antique gold coins. In: Sheedy KA, Davis G (eds) Mines, metals and money: ancient world studies in science, archaeology and history. Special publication, Royal Numismatic Society $56=$ Metallurgy in numismatics 6, London, pp 195-206

Blet-Lemarquand M, Nieto-Pelletier S, Téreygeol F (2014) Tracer l'or monnayé: le comportement des éléments traces de l'or au cours des opérations de refonte et d'affinage. Application à la numismatique antique, Bulletin de la Société française de Numismatique 69(4):9095

Blet-Lemarquand M, Suspène A, Amandry M (2015) Augustus' gold coinage: Investigating mints and provenance through trace element concentrations. In: Hauptmann A, Modarressi-Teherani D (eds) Archaeometallurgy in Europe III, Der Anschnitt, Beiheft 26, Bochum, pp 107-113

Blet-Lemarquand M, Nieto-Pelletier S, Téreygeol F, Suspène A (2017) Are platinum and palladium relevant tracers for ancient gold coins? Archaeometallurgical and archaeometric data to study an antique numismatic problem, in Archaeometallurgy in Europe IV (eds. I. Montero-Ruiz and A. Perea), 19-28, Bibliotheca praehistorica hispana 33, Consejo Superior de Investigaciones, Madrid

Borg G, Pernicka E, Ehser A, Lockhoff N, Camm GS, Smale CV (2019) From distant lands: provenance studies of natural gold in comparison to the gold of the Sky Disc of Nebra, in Der Aufbruch zu neuen Horizonten: Neue Sichtweisen zur europäischen Frühbronzezeit. Abschlusstagung der Forschergruppe FOR550 vom 26. bis 29. November 2010 in Halle (Saale) (eds. H. Meller and F. Bertemes), 55-78, Tagungen des Landesmuseum für Vorgeschichte Halle 19, Halle (Saale)

Bourgarit D, Thomas N (2008) Ancient brasses: misconceptions and new insights, in Archaeometallurgy in Europe III. Proceedings of the $3^{\text {rd }}$ International Conference. Deutsches Bergbau-Museum Bochum, June 29 - July 1, 2011, Deutsches Bergbau-Museum (eds. A. Hauptmann and D. Modarressi-Tehrani), 255-262, Der Anschnitt, Beiheft 26, Bochum

Brepohl E (1987) Theophilus Presbyter und die mittelalterliche Goldschmiedekunst, Edition Leipzig, Leipzig

Brügmann G, Brauns M, Maas R (2019) Silver isotope analysis of gold nuggets: an appraisal of instrumental isotope fractionation effects and potential for high-resolution tracing of placer gold. Chem Geol 516:59-67

Cauuet B, Tamas CG, Boussicault M, Munoz M (2018) Quantités et contrôle de l'or produit à l'âge du fer en Gaule du Centre-Ouest, in Dossier. Los metales preciosos: de la extracción a la acuñación (Antigüedad - Edad Media) (eds. C. Rico and A. Orejas), 13-42, Mélanges de la Casa de Velázquez: Nouvelle Série 48(1), Casa de Velázquez, Madrid

Celauro A, Loepp D, Ferro D (2017) Ancient procedures of gold cementation and gold scorification: considerations on their reliability through experimental archaeology, interpretation of chemical reactions and thermodynamics. Acta rerum naturalium 21:177-200

Chugaev AV, Chernyshev IV (2012) High noble measurement of ${ }^{107} \mathrm{Ag} /{ }^{109} \mathrm{Ag}$ in native silver and gold by multicollector inductively coupled plasma mass spectrometry (MC-ICP-MS). Geochem Int 50(11):899-910

Cowell MR, Hyne K (2000) Scientific examination of the Lydian precious metal coinages. In: Ramage A, Craddock PT (eds) King Croesus' gold: excavations at Sardis and the history of gold refining. British Museum Press, London, pp 169-174
Craddock PT (2000a) Historical survey of gold refining. In: Ramage A, Craddock PT (eds) King Croesus' gold: excavations at Sardis and the history of gold refining. British Museum Press, London, pp 27 53

Craddock PT (2000b) Replication experiments and the chemistry of gold refining. In: Ramage A, Craddock PT (eds) in King Croesus' gold: excavations at Sardis and the history of gold refining. British Museum Press, London, pp 175-183

Craddock PT (2000c) Reconstruction of the salt cementation process at the Sardis refinery. In: Ramage A, Craddock PT (eds) King Croesus' gold: excavations at Sardis and the history of gold refining. British Museum Press, London, pp 200-211

Craddock PT (2003) Cast iron, fined iron, crucible steel: liquid iron in the ancient world. In: Craddock PT, Lang J (eds) Mining and metal production through the ages. British Museum Press, London, pp 231-257

Desaulty AM, Albarède F (2013) Copper, lead, and silver isotopes solve a major economic conundrum of Tudor and early Stuart Europe. Geology 41(2):135-138

Desaulty AM, Telouk P, Albalat E, Albarède F (2011) Isotopic Ag-Cu-Pb record of silver circulation through $16^{\text {th }}-18^{\text {th }}$ century Spain. PNAS 108(22):9002-9007

Ehrlich S, Butler I, Halicz L, Rickard D, Oldroyd A, Matthews A (2004) Experimental study of the copper isotope fractionation between aqueous $\mathrm{Cu}(\mathrm{II})$ and covellite, CuS. Chem Geol 209(3-4):259-269

Geçkinli AE, Özbal H, Craddock PT, Meeks ND (2000) Examination of the Sardis gold and the replication experiments. In: Ramage A, Craddock PT (eds) King Croesus' gold: excavations at Sardis and the history of gold refining. British Museum Press, London, pp 184199

Gondonneau A, Nicolet-Pierre H, Guerra MF (2002) The Persian and Macedonian gold from Sarius to Alexander the Great. In: Jerem EM, Biró KT (eds) Archaeometry 98: Proceedings of the 31st Symposium Budapest, April 26 - May 3, 1998. BAR International Series, 1043 - Archaeolingua, 1, Archaeopress, Oxford, pp 369-374

Gramlich JW, Machlan LA, Barnes IL, Paulsen PJ (1989) Absolute isotopic abundance ratios and atomic weight of a reference sample of nickel. Journal of Research of the National Institute of Standards and Technology 94(6):347-356

Hartmann A (1970) Prähistorische Goldfunde aus Europa: Spektralanalytische Untersuchungen und deren Auswertung, Studien zu den Anfängen der Metallurgie, 3, Gebr. Mann Verlag, Berlin

Hartmann A (1978) Ergebnisse spektralanalytischer Untersuchung späthallstatt- und laténezeitlicher Goldfunde vom Dürrnberg, aus Südwestdeutschland, Frankreich und der Schweiz, in Der Dürrnberg bei Hallein 3: Auswertung der Grabfunde (L. Pauli), 601-617, Münchner Beiträge zur Vor- u. Frühgeschichte 18,1, München

Hartmann A (1982) Prähistorische Goldfunde aus Europa II: Spektralanalytische Untersuchungen und deren Auswertung, Studien zu den Anfängen der Metallurgie, 5, Gebr. Mann Verlag, Berlin

Hatchfield P, Newman R (1991) Ancient Egyptian gilding methods, in Gilded wood: conservation and history (eds. D. Bigelow, E. Corn, G. J. Landrey and C. van Home), 27-47, Sound View Press, Madison

Hawthorne JG, Smith CS (1979) Theophilus: on divers arts. The foremost medieval treatise on painting, glassmaking and metalwork, Dover Publications, New York

Herodotus and Cary H (Trans.) (1904) The Histories of Herodotus, D. Appleton and Company, New York

Himmelmann, U. (2015) Seiner Geschichte beraubt - der spätantike Schatzfund von Rülzheim, in Wissensgesellschaft Pfalz: 90 Jahre Pfälzische Gesellschaft zur Förderung der Wissenschaften (eds. P. Diehl, A. Imhoff and L. Möller), 165-174, Veröffentlichungen der 
Pfälzischen Gesellschaft zur Förderung der Wissenschaften 116, Heidelberg

Hisham MWM, Benson SW (1995) Thermochemistry of the Deacon process. J Phys Chem 99(16):6194-6198

Hoefs J (2018) Stable isotope geochemistry, Springer, Cham

Hough RM, Butt CRM, Fisher-Buhner J (2009) The crystallography, metallography and composition of gold. Elements 5:297-302

Jansen, M (2019) Geochemie und Archäometallurgie des Goldes der Bronzezeit in Vorderasien, $\mathrm{PhD}$ thesis, Ruhr University Bochum

Kavner A, John SG, Sass S, Boyle EA (2008) Redox-driven stable isotope fractionation in transition metals: application to $\mathrm{Zn}$ electroplating. Geochim Cosmochim Acta 72(7):1731-1741

Kelly WR, Wasserburg GJ (1978) Evidence for the existence of ${ }^{107} \mathrm{Pd}$ in the early solar system. Geophyical Research Letters 5(12):10791082

Klein S, Brey GP, Durali-Müller S, Lahaye Y (2010) Characterisation of the raw metal sources used for the production of copper and copperbased objects with copper isotopes. Archaeol Anthropol Sci 2:45-56

Klemm DD, Gebhard R (2001) Anhang II: Analyse des Goldes; Anhang III: Analyse der Vergoldung, in Das Geheimnis des goldenen Sarges: Echnaton und das Ende der Amarnazeit (eds. A. Grimm and S. Schoske), 80-86, Schriften aus der Ägyptischen Sammlung 10, Staatliches Museum Ägyptischer Kunst, München

Konstantinidi-Syvridi E, Papadimitriou N, Philippa-Touchais A, Goumas A (2014) Goldworking techniques in Mycenaean Greece $\left(17^{\text {th }} / 16^{\text {th }}\right.$ $12^{\text {th }}$ century BC): some new observations, in Metalle der Macht: Frühes Gold und Silber. 6. Mitteldeutscher Archäologentag vom 17. bis 19. Oktober 2013 in Halle (Saale) (eds. H. Meller, R. Risch and E. Pernicka), 335-348, Tagungen des Landesmuseums für Vorgeschichte Halle Band 11, Landesmuseum für Vorgeschichte Halle, Halle (Saale)

Leusch V, Brauns B, Pernicka E (2016) Precise and accurate analysis of gold alloys: Varna, the earliest gold of mankind - a case study, in Recent advances in laser ablation ICP-MS for archaeology (eds. L. Dussubieux, M. Golitko and B. Gratuze), 95-113, Natural Science in Archaeology, Berlin

Maréchal CN, Télouk P, Albarède F (1999) Precise analysis of copper and zinc isotopic compositions by plasma-source mass spectrometry. Chem Geol 156(1-4):251-273

Markl G, Lahaye Y, Schwinn G (2006) Copper isotopes as monitors of redox processes in hydrothermal mineralization. Geochim Cosmochim Acta 70(16):4215-4228

Mathur R, Dendas M, Titley S, Phillips A (2010) Patterns in the copper isotope composition of minerals in porphyry copper deposits in Southwestern United States. Econ Geol 105(8):1457-1467

Mathur R, Arribas A, Megaw P, Wilson M, Stroup S, Meyer-Arrivillaga D, Arribas I (2018) Fractionation of silver isotopes in native silver explained by redox reactions. Geochim Cosmochim Acta 224:313326

Meeks N (2000) Scanning electron microscopy of the refractory remains and the gold. In: Ramage A, Craddock PT (eds) King Croesus' gold: excavations at Sardis and the history of gold refining. British Museum Press, London, pp 99-156

Milcent PY (2018) L'or hallstattien dans le temps et l'espace: lecture archéologique des découvertes de métal précieux dans le domaine hallstattien central et occidental $\mathrm{VIII}^{\mathrm{e}}-\mathrm{V}^{\mathrm{e}} \mathrm{s}$. av. J.-C in Early Iron Age gold in Celtic Europe: society, technology and archaeometry. Proceedings of the International Congress held in Toulouse, France, 11-14 March 2015 (eds. R. Schwab, P.-Y. Milcent, B. Armbruster and E. Pernicka), 43-91, Forschungen zur Archäometrie und Altertumswissenschaft 6.1, Rahden/Westf

Milot J, Malod-Dognin C, Blichert-Toft J, Télouk P, Albarède F (2021) Sampling and combined $\mathrm{Pb}$ and $\mathrm{Ag}$ isotopic analysis of ancient silver coins and ores. Chem Geol 564:120028

Moynier F, Vance D, Fujii T, Savage P (2017) The isotope geochemistry of zinc and copper. Rev Mineral Geochem 82(1):543-600
Notton JHF (1974) Ancient Egyptian gold refining: a reproduction of early techniques. Gold Bull 7:50-56

Ogden J (1976) The so-called 'platinum' inclusions in Egyptian goldwork. J Egypt Archaeol 62(1):138-144

Ogden J (1977) Platinum group metal inclusions in ancient gold artifacts. Journal of the Historical Metallurgy Society 11(2):53-70

Pan JD, Balluffi RW (1982) Diffusion induced grain boundary migration in $\mathrm{AuCu}$ and $\mathrm{AuAg}$ thin films. Acta Metallurgica 30(4):861-870

Pernicka E (2014) On the authenticity of the gold finds from Bernstorf, community of Kranzberg, Freising district, Bavaria. Jahresschrift für mitteldeutsche Vorgeschichte 94:517-526

Pernicka E, Bachmann H-G (1983) Archäometallurgische Untersuchungen zur antiken Silbergewinnung in Laurion: Teil III. Das Verhalten einiger Spurenelemente beim Abtreiben des Bleis, Erzmetall 36:592-597

Pernicka E, Leusch V, Lockhoff N (2019) Die Goldscheibe von Moordorf und die Goldfunde der europäischen Bronzezeit, Die Kunde N. F. 67:117-135

Ramage A, Craddock PT (2000) King Croesus' gold: excavations at Sardis and the history of gold refining, British Museum Press, London

Reinecke A (2019) [雷安迪], and Lockhoff, N. [卢可] Latest research on early gold artefacts discovered in the southern part of Vietnam [ 越南 南部出土西汶吋期金器的最新研究], in Archaeology of the maritime silk road in Han Dynasty and Han Culture [汉代海上丝绸之路考古与 汉文化] (eds. Bai Yunxiang [白云翔], Xie Riwan [谢日万], Hong Shi [洪石], Lin Qiang [林强], 446-451, Beijing

Reinecke, A., Lychour, V., Lockhoff, N., 2019, Das goldene Erbe von Prohear (Kambodscha), in Ergrabene Welten: 40 Jahre archäologische Spurensuche auf vier Kontinenten (ed. Deutsches Archäologisches Institut, KAAK), 164-173, Bonn

Richter FM, Dauphas N, Teng F-Z (2009) Non-traditional fractionation of non-traditional isotopes: evaporation, chemical diffusion and Soret diffusion. Chem Geol 258(1-2):92-103

Russell WA, Papanastassiou DA, Tombrello TA (1978) Ca isotope fractionation on the Earth and other solar system materials. Geochim Cosmochim Acta 42(8): 1075-1090

Sarah G, Gratuze B, Barrandon J-N (2007) Application of laser ablation inductively coupled plasma mass spectrometry (LA-ICP-MS) for the investigation of ancient silver coins. J Anal At Spectrom 22(9): 1163-1167

Schleicher NJ, Dong S, Packman H, Little SH, Gonzalez RO, Najorka J, Sun Y, Weiss DJ (2021) A global assessment of copper, zinc, and lead isotopes in mineral dust sources and aerosols. Frontiers in Earth Science 8:2020. https://doi.org/10.3389/feart.2020.00167

Schlosser S, Reinecke A, Schwab R, Pernicka E, Sonetra S, Laychour V (2012) Early Cambodian gold and silver from Prohear: composition, trace elements and gilding. J Archaeol Sci 39(9):2877-2887

Schmiderer, A (2008) Geochemische Charakterisierung von Goldvorkommen in Europa, Ph.D. thesis University HalleWittenberg

Schönbächler M, Carlson RW, Horan MF, Mock TD, Hauri EH (2010) Heterogeneous accretion and the moderately volatile element budget of earth. Science 328(5980):884-887

Schwab R, Pernicka E (2021) Metallanalysen an den Goldfunden aus der Gruft VII und der Königsgruft von Qațna, in Gold von Königen und Göttern: Zur Bedeutung von Goldobjekten in den syrischnordlevantinischen Königtümern der Mittleren und Späten Bronzezeit ausgehend von den Funden aus den Grüften von Qața (ed. I. Puljiz), 557-581, Qațna Studien 10, Wiesbaden

Soukup RW, Mayer H (1997) Alchemistisches Gold - Paracelsistische Pharmaka: Laboratoriumstechnik im 16. Jahrhundert. Chemiegeschichtliche und archäometrische Untersuchungen am Inventar des Laboratoriums von Oberstockstall/Kirchberg am Wagram, Perspektiven der Wissenschaftsgeschichte, Böhlau, Wien 
Stöllner T (2018) Weißes Gold: Zum Neufund“ einer Gussform für Goldbarren vom Dürrnberg bei Hallein, Österreich, in Faber Salisburgi: Festschrift für Wilfried K. Kovacsovics zum 65. Geburtstag (eds. R. Kastler, F. Lang and H. Wendling), 297-304, ArchaeoPlus $10=$ Salzburg Studien Forschungen zu Geschichte, Kunst und Kultur 18, Salzburg

Tiefengraber G, Wiltschke-Schrotta, K (2012) Der Dürrnberg bei Hallein: Die Gräbergruppe Moserfeld-Osthang, Dürrnberg-Forschungen 6, Rahden/Westfalen

Troalen LG, Guerra MF, Tate J, Manley B (2009) Technological study of gold jewellery pieces dating from the Middle Kingdom to the New Kingdom in Egypt, in Authentication and analysis of gold work (eds. M. F. Guerra and T. Rehren), 111-119, ArcheoSciences: Revue d'archéométrie 33, Presses universitaires de Rennes et ArcheoSciences, Rennes

Vîlcu A, Constantinescu B, Bugoi R, Păuna C (2010) Some considerations on Dacian gold coins of Koson type in the light of compositional analyses, Revue Numismatique, 6e. Série 166:297-310

Voisey CR, Maas R, Tomkins AG, Brauns M, Brügmann G (2019) Extreme silver isotope variation in orogenic gold systems implies multistaged metal remobilization during ore genesis. Econ Geol 114(2):233-242
Wiederhold JG (2015) Metal stable isotope signatures as tracers in environmental geochemistry. Environ Sci Technol 49(5):2606-2624

Wunderlich CH, Lockhoff N, Pernicka E, (2014) De cementatione oder: Von der Kunst, das Gold nach Art der Alten zu reinigen, in Metalle der Macht: Frühes Gold und Silber. 6. Mitteldeutscher Archäologentag vom 17. bis 19. Oktober 2013 in Halle (Saale) (eds. H. Meller, R. Risch and E. Pernicka), 353-366, Tagungen des Landesmuseums für Vorgeschichte Halle 11, Landesmuseum für Vorgeschichte Halle, Halle (Saale)

Zhou S, Wei Y, Wang H, Ma B, Wang C (2016) Mechanism of sodium chloride in promoting reduction of high-magnesium low-nickel oxide ore. Nat Sci Rep 6(29061):1-12

Zhu XK, O’Nions RK, Guo Y, Belshaw NS, Rickard D (2000) Determination of natural $\mathrm{Cu}$-isotope variation by plasma-source mass spectrometry: implications for use as geochemical tracers. Chem Geol 163(1-4):139-149

Publisher's note Springer Nature remains neutral with regard to jurisdictional claims in published maps and institutional affiliations. 